\title{
Systematic Cavitation Tunnel Tests of a Propeller in Uniform and Inclined Flow Conditions as Part of a Round Robin Test Campaign
}

\author{
Batuhan Aktas ${ }^{1}$, Mehmet Atlar ${ }^{1}$, Serkan Turkmen ${ }^{1}$, Emin Korkut ${ }^{2}$, Patrick Fitzsimmons ${ }^{1}$ \\ ${ }^{I}$ School of Marine Science and Technology, Newcastle University, Newcastle upon Tyne NE1 7RU, UK \\ ${ }^{2}$ Istanbul Technical University, Faculty of Naval Architecture and Ocean Engineering, 34469 Maslak-Istanbul, Turkey
}

\begin{abstract}
The effect of shaft inclination can induce important unsteady hydrodynamic phenomenon usually associated with small and high-speed craft. This paper presents systematic cavitation tunnel tests with a $214 \mathrm{~mm}$ diameter model propeller of a catamaran research vessel. The propeller is subjected to uniform and inclined flow conditions, to investigate its efficiency, cavitation and underwater radiated noise characteristics. The experiments were conducted in the Emerson Cavitation Tunnel of Newcastle University based on the starboard 5-bladed right-hand propeller of the University's research vessel, The Princess Royal. In the paper the details of the tests and significant findings for the effect of the shaft inclination on the propeller efficiency, cavitation and underwater radiated noise characteristics are presented. A better understanding is sought in relation to the noise signatures of different types of cavitation.
\end{abstract}

The systematic tests presented in the paper also have a long-term objective, being the first of an organized round robin test campaign that is being currently undertaken by the members of the Underwater Noise Community of Practice (CoP) of Hydro-Testing Forum (HTF). This long-term objective is to repeat similar tests in the different facilities of all CoP members to reveal the relative merits of their testing facilities for underwater noise investigations.

Keywords: Cavitation, Underwater radiated noise, Inclined shaft effect, Systematic propeller tests, Round robin noise tests

\section{INTRODUCTION}

The ambient noise levels of the world seas have been increasing. Amongst various sources contributing to this trend the low frequency contributions due to increasing shipping noise have been a recent concern since the low frequency range of the underwater noise spectrum is also used by marine mammals for their communications (IMO, 2011; MEPC, 2009). This fact has been expected to harm the survivability of marine mammals in the long term (Hildebrand, 2005).

As far as shipping noise is concerned, there are various sources on board a vessel. Amongst these sources propeller cavitation is considered to be the dominating one in contributing to the overall radiated noise spectrum above the cavitation inception threshold. Except for a singing propeller, this overshadows the other sources and produces a significant rise in the sound levels over the noise spectrum (Abrahamsen, 2012; Arveson \& Vendittis, 2000).

Some recent noise measurement campaigns have used opportunistic approaches to compile a full-scale noise database for commercial shipping. This has been achieved by deploying a hydrophone close to a marine traffic way and combining the noise data recorded with data from the ship's Automatic Identification Systems (AIS) (McKenna, Ross, Wiggins, \& Hildebrand, 2012; MCR, 2011). The results of such campaigns have indicated a difference of 20-40 dB within the same type of commercial vessels indicating that ship noise levels are not readily associated with AIS-type data. More detailed knowledge is required of the flow environment for which each propeller has been designed such that in the design stage, information can be gained which can then be used to control the propeller performance in terms of unwanted levels of cavitation and noise.

Increasing environmental concerns for potential harm to marine biodiversity have recently targeted propeller cavitation noise from commercial shipping. As a result there has been a concentration of attention in the field of underwater radiated noise and mitigation measures through co-operative research and workshop activities at local, European and international levels. These include organisational bodies such as International Maritime Organisation (IMO) (IMO, 2011), Marine Environmental Protection Committee (MEPC) (MEPC, 2009), European Marine Strategy Framework Directive (MSFD), $27^{\text {th }}$ International Towing Tank Conference (ITTC) (ITTC 2014), Hydro-Testing Alliance Network of Excellence (HTANoE) (AMT 2011), Hydro-Testing Forum (HTF) (AMT 2013) etc. 
In complementing the above activities the Joint Research Programme (JRP)10, named "Noise Measurements", was established within the Hydro Testing Alliance Network of Excellence (HTA-NoE) and successfully completed its mission in 2011 (AMT 2011). Subsequently, the members of JRP10 decided to form a working group to further investigate underwater radiated noise issues. This working group, which was initially named "Noise Working Group" (NWG), later became "Noise Community of Practice (Noise CoP)" of the Hydro Testing Forum (HTF) as a longer continuation of the HTA-NoE, which was phased out by then (AMT 2013). The first important task of the Noise CoP has been to undertake a round robin test campaign to investigate the cavitation and noise characteristics of the model propeller of Newcastle University (UNEW)'s Deep-V type catamaran research vessel, The Princess Royal. The main stimulus for this task was that the Noise CoP members have diverse testing facilities and The Princes Royal and its associated data are easily accessible. Moreover The Princess Royal has been providing a focus to be a benchmark vessel through various collaborative research activities e.g. the Cooperative Research Ships (CRS) consortium and the EC-FP7 SONIC project consortium (SONIC, 2012), in which some of the Noise CoP members are also participants, and hence this could provide further complementary exploitation opportunities within the CoP.

The above status and readily available scaled propeller model of The Princess Royal have made it beneficial to conduct a systematic round robin cavitation test campaign. In order to investigate unsteady flow effects the CoP decided to test the model propeller in uniform but systematically varied inclined shaft (or flow) conditions since the effect of shaft inclination is an important unsteady hydrodynamic phenomenon usually associated with small high speed craft. This would provide the CoP members with an opportunity to test the same propeller in different facilities and hence to compare its efficiency performance, cavitation and noise characteristics. Furthermore the results of the entire test campaign will enable the members to quantify the basic differences in their measurements and hence to investigate the relative merits of their facilities.

The initial experiments of this round robin model test campaign were conducted in the Emerson Cavitation Tunnel of Newcastle University based on modelling the starboard hull of The Princess Royal with its 5-bladed right-handed model propeller. Seven different shaft inclination angles $(\theta)$ were systematically varied in uniform flow ranging from $+9^{\circ}$ to $9^{\circ}$ over 3 different cavitation numbers $\left(\sigma_{V}=13.9,8.1,4.5\right)$ and 8 different advance coefficients $(J)$ ranging from 0.4 to 0.75 .

This paper presents the details and results of the first test campaign conducted by Newcastle University. Section 2 gives a short literature review of research work on inclined shaft effects on propellers. Section 3 presents a description of the experimental set-up and test conditions. Section 4 includes open water propeller performance results, while Section 5 gives cavitation observations. Section 6 presents noise measurements, Section 7 gives a discussion of results and finally Section 8 draws conclusions from the study.

\section{INCLINED SHAFT EFFECT ON PROPELLERS}

The inclined shaft effect and flow on a propeller is a well-known unsteady flow phenomenon that can occur either due to reasons of design configuration or to motions of the vessels whilst underway. Shaft inclinations may be imposed by the engine arrangements, the need for sufficient shaft submergence, for vertical propeller tip clearance with the hull or for improving the wake flow to the propeller. On the other hand vessel motions can be caused due to the stern wave, dynamic trim, pitching and heaving in heavy seas, and yawing and drifting of the vessel during maneuvering. Figure 1 shows a sketch to describe some fundamentals of the inclined flow phenomenon. 

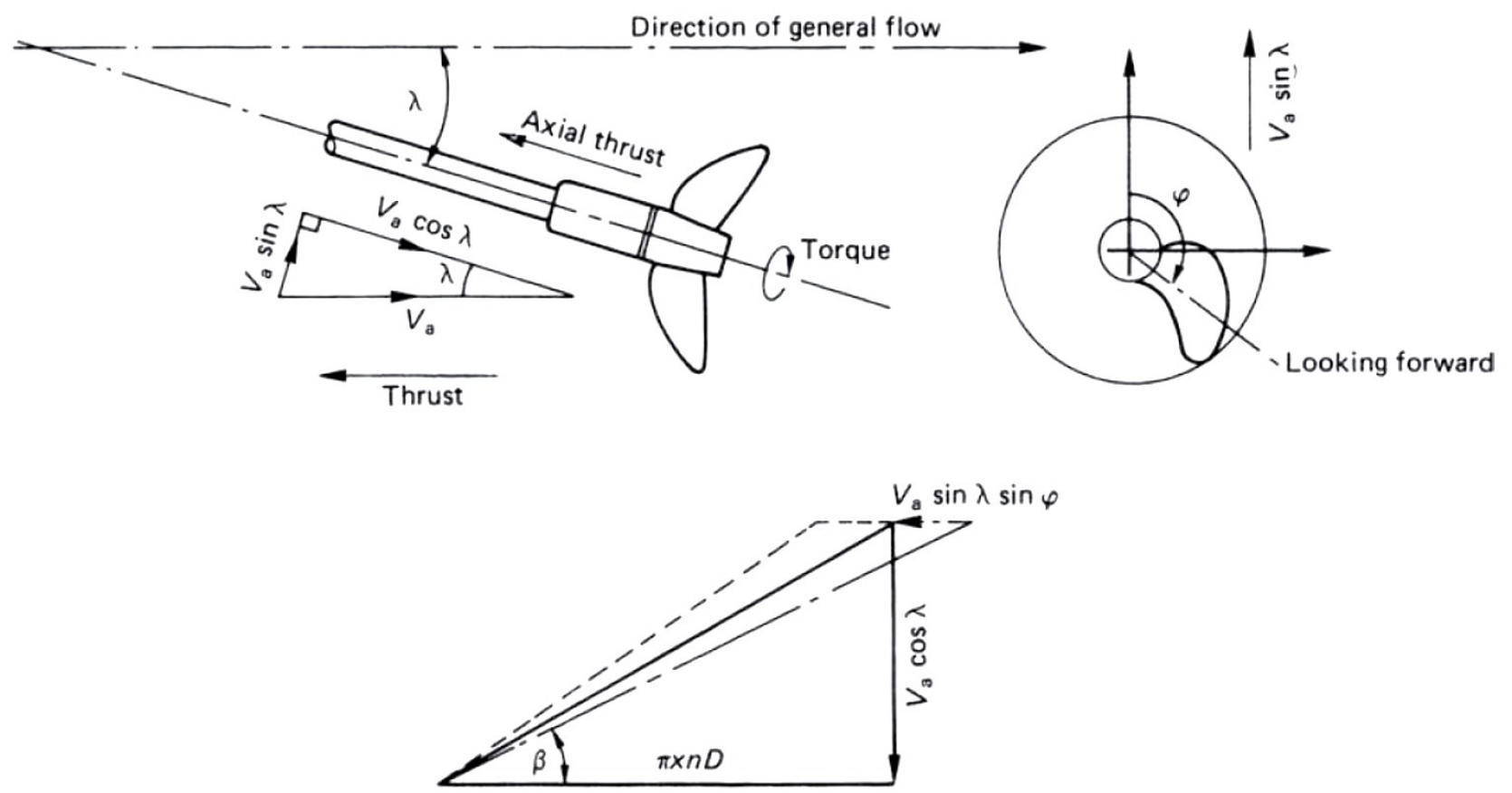

Figure 1 Inclined Flow Effect (Carlton 2012)

As shown in Figure 1 the effect of inclined flow manifests itself as a cyclic variation of the inflow angle to the propeller. This effect is more severe at the inner radii since the tangential velocity variation there becomes a greater percentage of the shaft rotational vector, compared to the blade tips. The oblique flow increases the angle of attack variation and hence the detrimental effects of inclined flow to the propeller sections will generate different kinds of cavitation phenomena leading to a range of cavitation and radiated noise issues.

The literature on shaft inclination has generally explored the cavitation extent and overall performance (thrust, torque) of a marine propeller. The related studies mainly concentrated on the validation of the inclined flow theory proposed by Gutsche (1964). The investigations reported in e.g. (Hadler 1966, Kozhukharov \& Sadovnokiov 1983) are typical of these studies. The investigations conducted by (Taniguchi et al. 1969) and Kozhukharov \& Sadovnokiov (1983) also involved extensive experiments in validating Gutsche's quasi-steady flow theory.

In his pioneering work Gutsche conducted a combination of theoretical and experimental research work involving six model propellers. The propellers selected were varied in terms of the blade area ratio (BAR), pitch to diameter ratio $(P / D)$ and all had a $200 \mathrm{~mm}$ diameter. The simulated shaft inclination angles were chosen as $0^{\circ}, 20^{\circ}$ and $30^{\circ}$. By utilizing the experimental data a quasi-steady flow analysis method was developed. The explanatory English description of Gutsche's study can be found in (Hadler, 1966). Taniguchi et. al's experimental investigation was conducted in the Mitsubishi Experimental Tank using 5 super cavitating propellers with different $P / D$ and $E A R$ ratios. The propellers were subjected to relatively smaller shaft inclination angles of $0^{\circ}, 4^{\circ}$ and $8^{\circ}$ (Taniguchi et al. 1969).

Even though one may find further examples of other experimental studies, as reported e.g. in (Carlton, 2012), the study conducted by (Kozhukharov \& Sadovnikov, 1983) carries greater importance due to the detailed cavitation sketches included for the conditions tested. The results obtained from the selected systematic series of cavitating screw propellers, that were developed using a lifting surface code, were used for populating the data and a validation study was conducted using the quasi-steady Gutsche method.

Even though the inclined flow effects can cause serious performance problems for a propeller such as: loss of thrust; erosion; intensified cavitation; and thrust and torque fluctuations, a comprehensive experimental investigation on the inclined phenomenon in a systematic manner, so far, has been rather scarce. Underwater radiated noise data is even scarcer. The present assessment of propeller cavitation and noise characteristics at different flow inclinations provides an essential body of such missing data. 


\section{EXPERIMENTAL SET UP \& TEST CONDITIONS}

Experiments were carried out in three groups of tests at the Emerson Cavitation Tunnel (ECT) of Newcastle University (UNEW), which has a large test section with a cross-sectional area of $1.22 \mathrm{~m}$ by $0.81 \mathrm{~m}(\mathrm{BxH})$ as shown in Figure 2 . Further details of the tunnel including the recent enhancements are given in Atlar (2011).

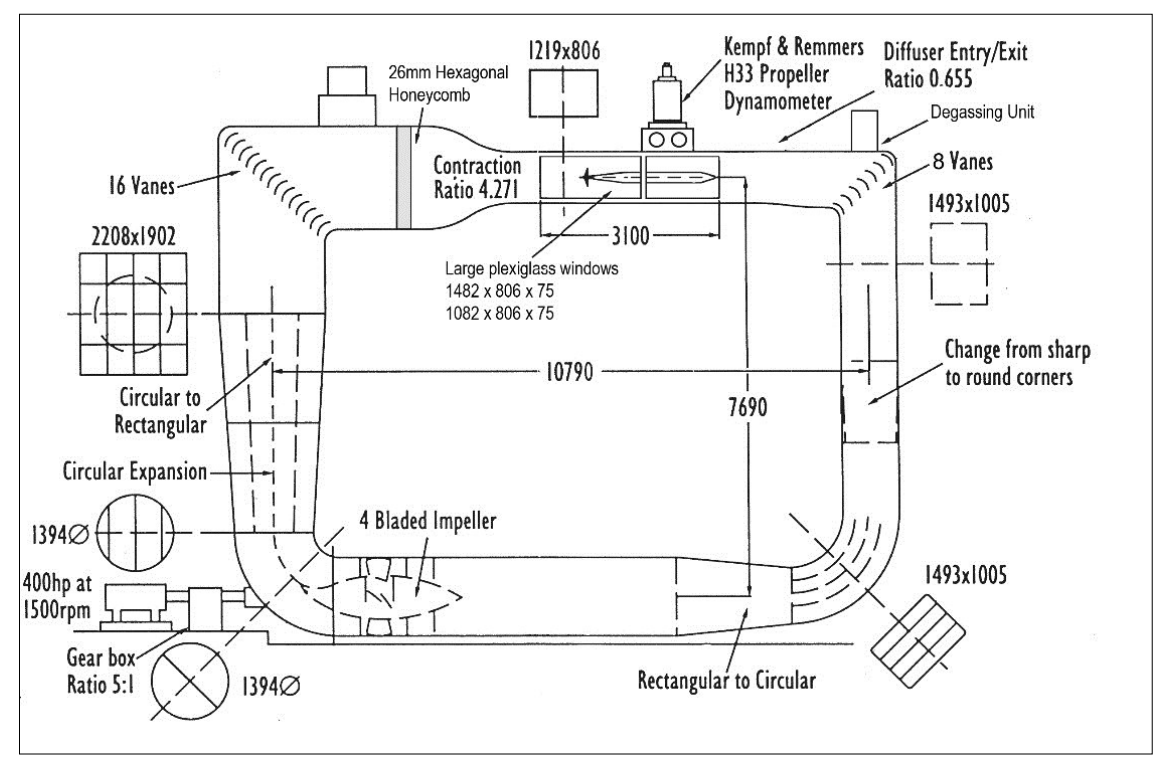

Figure 2 Emerson Cavitation Tunnel (Atlar, 2011)

The first group of these tests was to obtain the open water efficiency performance of the model propeller in systematically varied shaft inclination angles at 3 different vacuum levels (cavitation numbers) and hence to investigate the effect of the flow inclination and cavitation on the propeller performance. The second group of tests involved cavitation inception measurements with the model propeller under the same inclination and vacuum conditions. The third group of tests comprised the underwater noise measurements with the model propeller, once again, under the same flow and vacuum conditions. All of the tests were conducted at a $4 \mathrm{~m} / \mathrm{s}$ tunnel inflow speed recorded at the measuring section and for advance coefficients $(J)$ ranging from 0.4 to 0.75 . Table 1 gives an overall summary of the test conditions. The cavitation number $\left(\sigma_{V}\right)$ given in Table 1 is defined as follows:.

$$
\sigma_{V}=\frac{P_{a}+\rho g h_{s}-P_{v}}{0.5 \rho V^{2}}
$$

Where $P_{a}$ is the Atmospheric pressure; $\rho$ is the density of water, $g$ is the gravitational acceleration, $h_{s}$ is the shaft immersion of the propeller, $P_{v}$ is the vapour pressure, $V$ is the tunnel inflow velocity.

The propeller centre was always positioned on the tunnel centreline.

Table 1 the angle convention adopted for the shaft inclination during the tests was: a positive angle represented the case that the dynamometer shaft was inclined in an upward direction with the blade tip at the 6 o'clock position moving towards the incoming flow whilst a negative angle indicated the opposite (downward) direction.

The experiments were repeated for both negative and positive angles in order to account for the tunnel's speed profile at the propeller plane as shown in Figure 3. The propeller centre was always positioned on the tunnel centreline.

Table 1 A summary of test conditions

\begin{tabular}{|c|c|c|c|}
\hline & \multicolumn{3}{|c|}{ Test Type } \\
\hline & Open water performance tests & $\begin{array}{c}\text { Cavitation inception tests and } \\
\text { observations }\end{array}$ & Noise measurements \\
\hline Shaft Incl. Angle $\left({ }^{\circ}\right)$ & \multicolumn{3}{|c|}{$0,3,6,9,-3,-6$ and -9} \\
\hline Cavitation Condition & $\begin{array}{c}\text { Atmospheric condition } \\
\qquad\left(\sigma_{\mathrm{V}}=13.9\right)\end{array}$ & $\begin{array}{l}\text { Medium vacuum condition } \\
\qquad\left(\sigma_{\mathrm{V}}=8.1\right)\end{array}$ & $\begin{array}{l}\text { High vacuum condition } \\
\text { corresponding to vessel's fully } \\
\text { loaded condition } \\
\left(\sigma_{\mathrm{V}}=4.5\right)\end{array}$ \\
\hline J Range Tested & \multicolumn{3}{|c|}{$0.75,0.70,0.65,0.60,0.55,0.50,0.45,0.40$} \\
\hline
\end{tabular}




\subsection{Propeller Design and Model Propeller}

The propeller model used for the cavitation tunnel tests represented the starboard side propeller of The Princess Royal with a scale ratio of 3.5 , giving a $214 \mathrm{~mm}$ model propeller diameter. This model was manufactured with a high accuracy for cavitation testing. Figure 4 shows the model propeller together with the full-scale port side propeller. The principal dimensions of the propeller and the vessel are given in Table 2 and

Table 3, respectively, (Atlar et al., 2013). The loading condition in Table 3 corresponds to the light load departure condition of the vessel.

Table 2 Main particulars of the propellers of The Princess Royal

\begin{tabular}{|c|c|}
\hline \multicolumn{1}{|c|}{ Propeller } \\
\hline Diameter, D & $0.75 \mathrm{~m}$ \\
\hline Pitch Ratio at 0.7R, P/D & 0.8475 \\
\hline Expanded Blade Area Ratio, $\mathrm{A}_{\mathrm{E}} / \mathrm{A}_{0}$ & 1.057 \\
\hline Number of Blades, $\mathrm{Z}$ & 5 \\
\hline Rake angle & $0^{\circ}$ \\
\hline Skew angle & $19^{\circ}$ \\
\hline Direction of rotation & 3.5 \\
\hline Scale ratio, $\lambda$ & 0.5 \\
\hline Design Advance Coefficient, J handed \\
\hline Material & $\mathrm{NiAlBr}$ \\
\hline
\end{tabular}

Table 3 Main particulars of The Princess Royal

\begin{tabular}{|c|c|}
\hline \multicolumn{1}{|c|}{ Vessel } & Catamaran \\
\hline Ship type & $16.45 \mathrm{~m}$ \\
\hline Length between perpendiculars, $\mathrm{L}_{\mathrm{PP}}$ & $16.523 \mathrm{~m}$ \\
\hline Length on water line, $\mathrm{L}_{\mathrm{WL}}$ & $7.03 \mathrm{~m}$ \\
\hline Breadth, $\mathrm{B}$ & $1.748 \mathrm{~m}$ \\
\hline Draught at mid-ship, $\mathrm{T}$ & $1.763 \mathrm{~m}$ \\
\hline Draught at aft perpendicular, $\mathrm{T}_{\mathrm{AP}}$ & $1.732 \mathrm{~m}$ \\
\hline Draught at forward perpendicular, $\mathrm{T}_{\mathrm{FP}}$ & 0.362 \\
\hline Block Coefficient, $\mathrm{C}_{\mathrm{B}}$ & $15 \mathrm{knots}$ \\
\hline Service speed, $\mathrm{V}_{\mathrm{S}}$ & Aluminium \\
\hline Material & \\
\hline
\end{tabular}




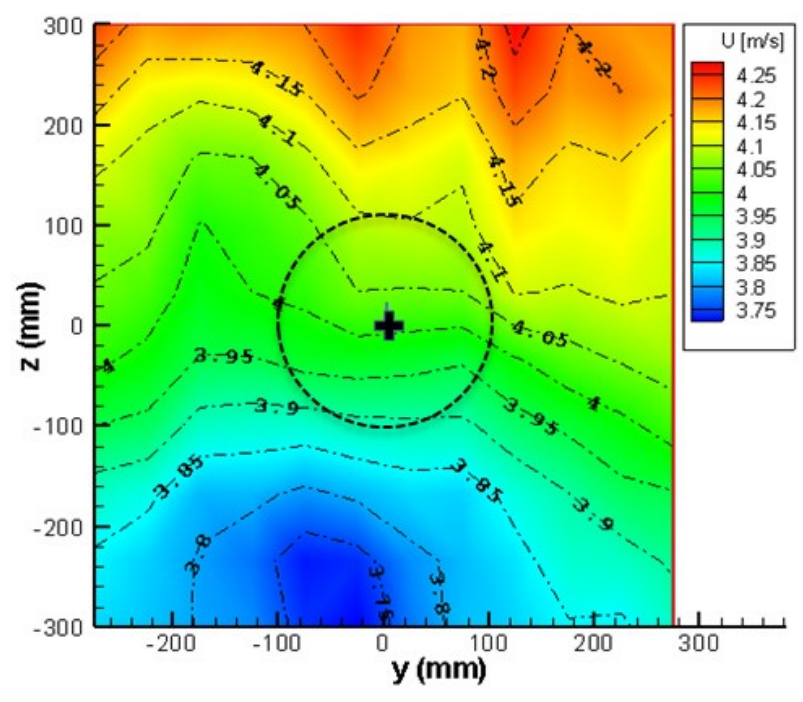

Figure 3 Axial speed profile of the Emerson Cavitation Tunnel for $4 \mathrm{~m} / \mathrm{s}$ inflow velocity measured at the propeller plane where the origin is the shaft centreline.

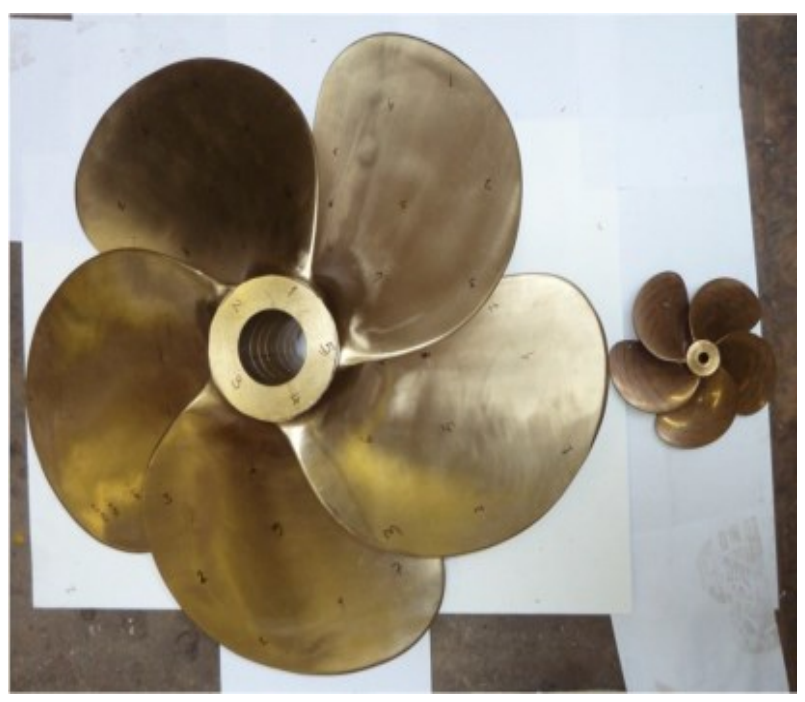

Figure 4 Views of full-scale (port) and model-scale (starboard) propellers of The Princess Royal

\section{OPEN WATER PERFORMANCE TESTS}

Open water performance tests to measure the thrust and torque of the model propeller were carried out according to the ITTC procedures for open water tests (ITTC, 2011), using a K\&R H33 dynamometer and Cussons Type H101-27 shaft height and angle adjustment system of the Emerson Cavitation Tunnel. The tests were performed to cover the whole advance coefficient $(J)$ range of the tunnel and systematic shaft angle combination under the Atmospheric and 2 additional different vacuum conditions as specified in Table 1. The tunnel inflow speed ( $V$ ) was kept at $4 \mathrm{~m} / \mathrm{s}$ and the advance coefficients $(J)$ were varied systematically by changing the rotational speed of the propeller $(n)$.

In order to achieve accurate results in the open water tests, the sampling rate for the measurements was $1000 \mathrm{~Hz}$. The tests were repeated 6 times for the level shaft under Atmospheric condition, and 3 times for the other conditions under vacuum, as stated in Table 1 . The thrust and torque values were then averaged and presented in non-dimensional coefficients: $K_{T}$ for thrust, $K_{Q}$ for torque and $\eta_{0}$ for propeller efficiency defined as:

$$
J=\frac{V}{n D} \quad K_{T}=\frac{T}{\rho n^{2} D^{4}} \quad K_{Q}=\frac{Q}{\rho n^{2} D^{5}} \quad \eta_{0}=\frac{J}{2 \pi} \frac{K_{T}}{K_{Q}}
$$

Where $\mathrm{T}$ is thrust, $\rho$ is the density of water, $\mathrm{Q}$ is the torque and $\mathrm{D}$ is the diameter of the propeller.

For the plotted advance coefficients a simple cosine correction was applied to the advance coefficients as $J_{\text {corrected }}=J$ $\cos \theta$, where $\theta$ is the shaft inclination angle. A typical representation of the open water performance curves for the high vacuum condition, whilst varying the shaft inclination angle, is shown in Figure 5. The full representation of the entire open water performance curves can be found in Aktas et al. (2014) 


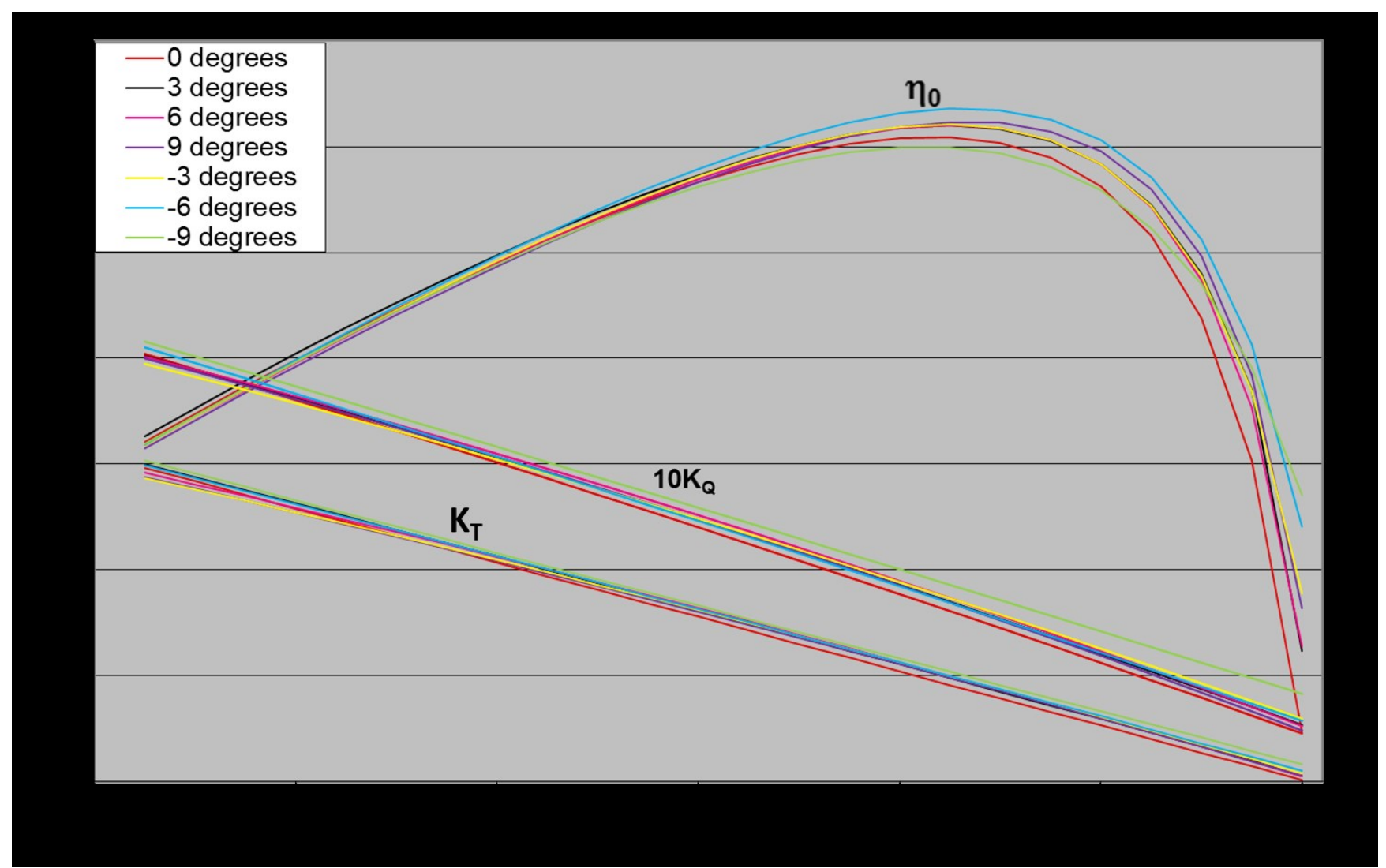

Figure 5 Open water performance of model propeller, for various inclination angles under high vacuum condition

During the tests the propeller Reynolds number $\left(R_{e}\right)$ range varied from $4.03 \times 10^{6}$ to $8.22 \times 10^{6}$. Here $R_{e}$ is defined based on the propeller chord length at $0.7 R$ as follows:

$$
R_{e}=\frac{C_{0.7 R} \sqrt{V^{2}+(0.7 \pi n D)^{2}}}{v}
$$

Where $c_{0.7 R}$ is the chord length at $0.7 R$ and $v$ is being the kinematic viscosity of tunnel water.

\section{CAVITATION OBSERVATIONS}

The cavitation observation recordings were made during the experiments both for cavitation inception/desinence detection and for well-developed cavitation. Two different configurations for the recordings were used: one using a strobe synchronised with a high-speed video camera; and the other using a continuous light source with the high-speed video camera. In the former configuration the cavitation images were captured using the TTL signal from the electric motor driving the shaft to trigger both the strobe and the high-speed video. In the latter a powerful continuous light was used with the high-speed video to obtain a better understanding of the cavitation dynamics. Figure 6 shows typical frames from the recordings made with a Dantec Dynamics Nanosense Mk II high-speed video camera (running at 2000 frames per second) for the cavitation developments at $-9^{\circ}$ inclination angle under the high vacuum condition for varying advance coefficients. A full set of such images, covering the entire test range, can be found in Aktas et al. (2014) 


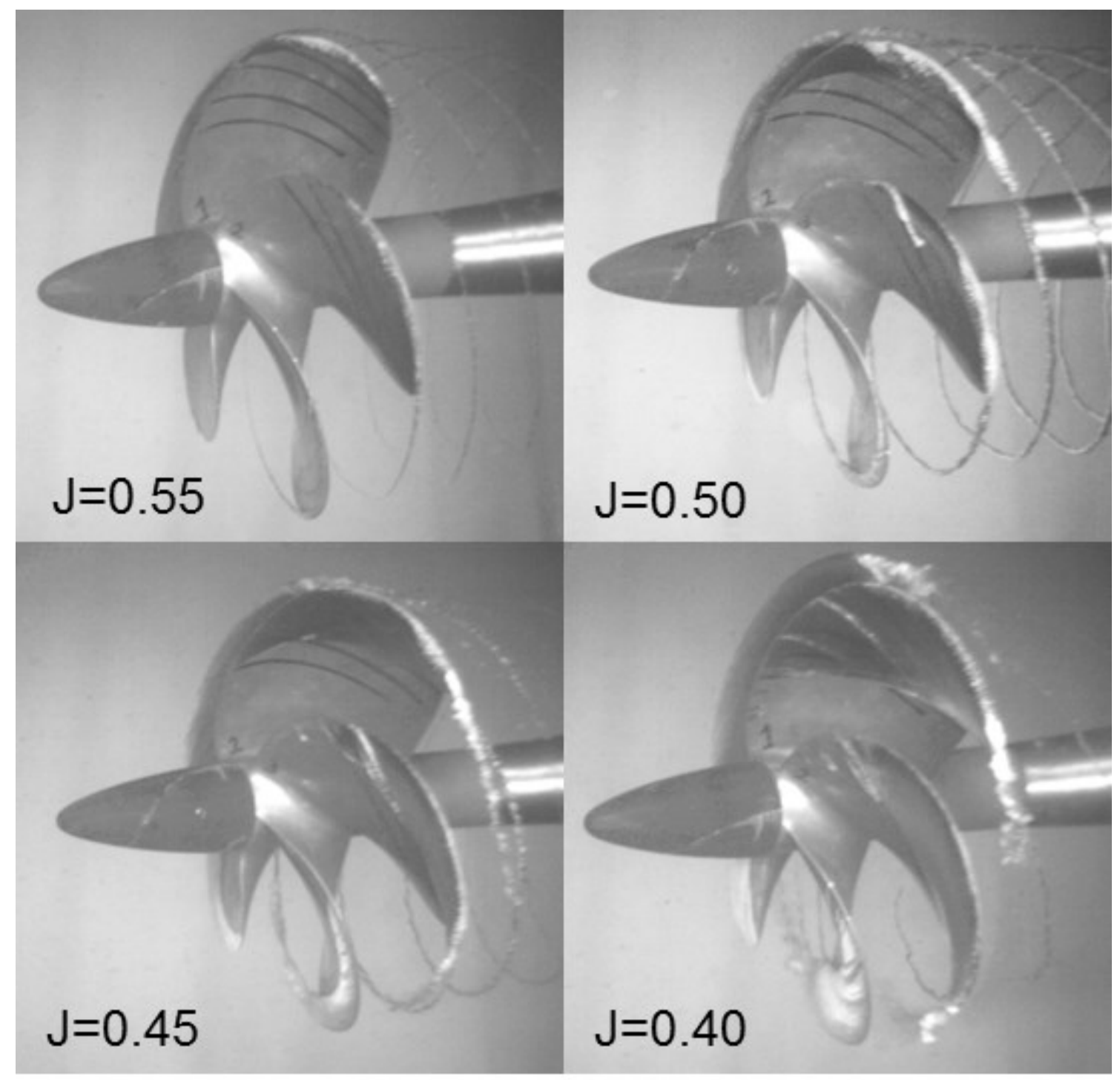

Figure 6 Cavitation developments at $-9^{\circ}$ inclination angle under high vacuum condition

\subsection{Cavitation Inception}

Inception and desinence points for respective cavitation events were recorded on video as well as by eye. The procedure for the inception measurements was performed such that the tunnel flow velocity was kept constant at $4 \mathrm{~m} / \mathrm{s}$. The tunnel static pressure was also set to a constant value and the rotational speed of the propeller was initially increased until a visual appearance of an unattached cavitating tip vortex cavitation was observed. This was recorded as the inception point of the respective cavitation. The rotational speed was then increased up to the point that the tip vortex attached to the blades and then was decreased until the vortex disappeared from the tip of the propeller. This was accepted as the desinence point of the cavitation. Typical images of the inception and desinence points are shown in Figure 7 for the propeller model at $0^{\circ}$ inclination angle under the high vacuum condition. The inception/desinence points for all of the tested conditions are presented in Table 4. 

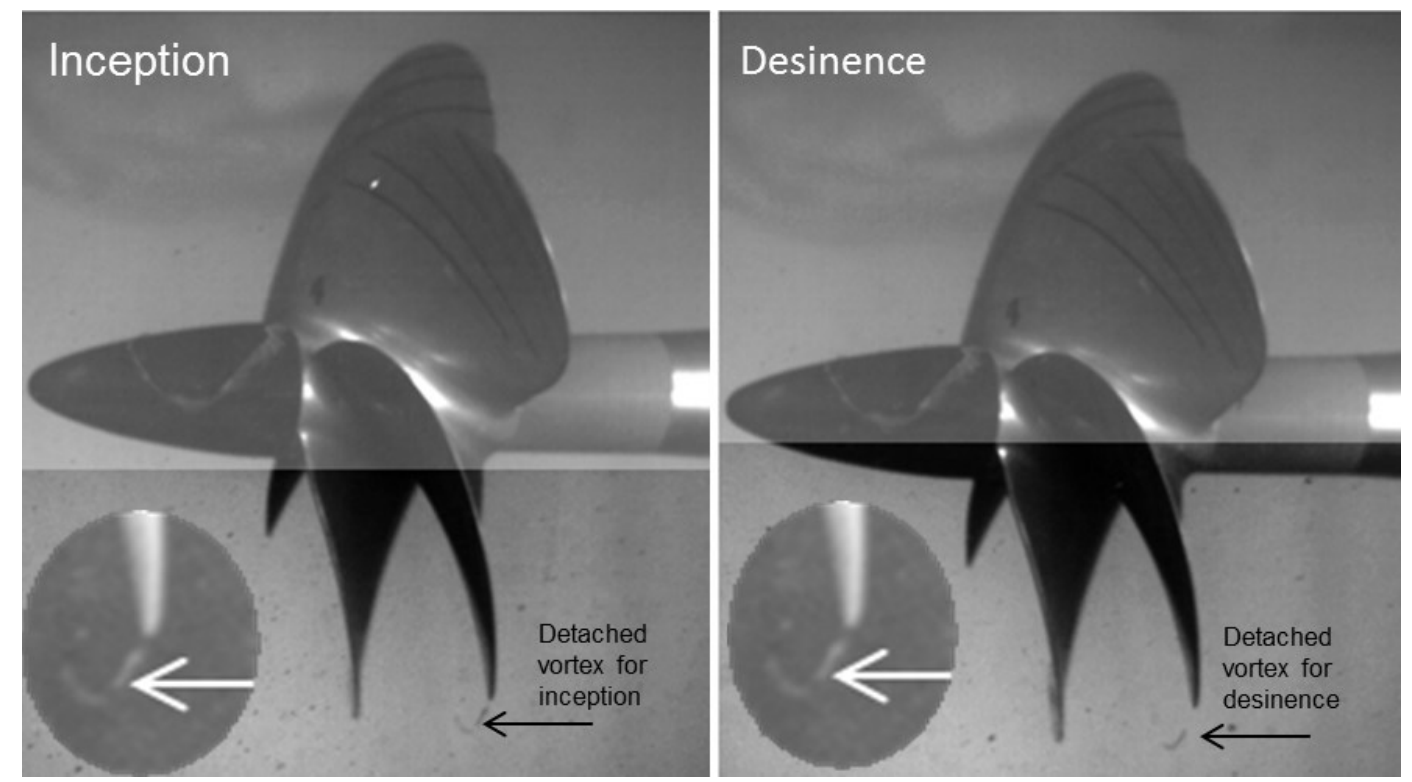

Figure 7 Images of the cavitation inception and desinence points for propeller model at $0^{\circ}$ inclination angle under high vacuum condition

Table 4 Cavitation inception and desinence points of propeller model at varying inclination angles and cavitation numbers

\begin{tabular}{|c|c|c|c|c|c|c|c|}
\hline \multicolumn{8}{|c|}{ Atmospheric condition } \\
\hline $\begin{array}{l}\text { Inclination } \\
\text { angle }\end{array}$ & $0^{\circ}$ & $3^{\circ}$ & $6^{\circ}$ & $9^{\circ}$ & $-3^{\circ}$ & $-6^{\circ}$ & $-9^{\circ}$ \\
\hline $\begin{array}{c}\text { Cavitation } \\
\text { Type }\end{array}$ & $\begin{array}{c}\text { Tip } \\
\text { Vortex }\end{array}$ & Tip Vortex & Tip Vortex & Tip Vortex & Tip Vortex & Tip Vortex & Tip Vortex \\
\hline $\begin{array}{c}\text { Inception } \\
(\mathrm{RPM})\end{array}$ & 2128 & 2102 & 2047 & 2003 & 2138 & 2165 & 2095 \\
\hline $\begin{array}{l}\text { Desinence } \\
(\mathrm{RPM})\end{array}$ & 2188 & 2126 & 2076 & 2093 & 2165 & 2186 & 2110 \\
\hline $\mathrm{J}_{\text {Inception }}$ & 0.527 & 0.534 & 0.548 & 0.56 & 0.525 & 0.518 & 0.535 \\
\hline$\sigma_{\text {Inception }}$ & 0.758 & 0.772 & 0.811 & 0.845 & 0.748 & 0.737 & 0.782 \\
\hline \multicolumn{8}{|c|}{ Medium Vacuum Condition } \\
\hline $\begin{array}{l}\text { Inclination } \\
\text { angle }\end{array}$ & $0^{\circ}$ & $3^{\circ}$ & $6^{\circ}$ & $9^{\circ}$ & $-3^{\circ}$ & $-6^{\circ}$ & $-9^{\circ}$ \\
\hline $\begin{array}{c}\text { Cavitation } \\
\text { Type }\end{array}$ & $\begin{array}{c}\text { Tip } \\
\text { Vortex }\end{array}$ & Tip Vortex & Tip Vortex & Tip Vortex & Tip Vortex & Tip Vortex & Tip Vortex \\
\hline $\begin{array}{c}\text { Inception } \\
(\mathrm{RPM})\end{array}$ & 2013 & 1916 & 1900 & 1860 & 2004 & 2013 & 1921 \\
\hline $\begin{array}{c}\text { Desinence } \\
\text { (RPM) }\end{array}$ & 2030 & 1946 & 1930 & 1938 & 2002 & 2030 & 1962 \\
\hline $\mathrm{J}_{\text {Inception }}$ & 0.557 & 0.585 & 0.59 & 0.603 & 0.56 & 0.557 & 0.584 \\
\hline$\sigma_{\text {Inception }}$ & 0.489 & 0.537 & 0.541 & 0.566 & 0.492 & 0.498 & 0.542 \\
\hline \multicolumn{8}{|c|}{ High Vacuum Condition } \\
\hline $\begin{array}{l}\text { Inclination } \\
\text { angle }\end{array}$ & $0^{\circ}$ & $3^{\circ}$ & $6^{\circ}$ & $9^{\circ}$ & $-3^{\circ}$ & $-6^{\circ}$ & $-9^{\circ}$ \\
\hline
\end{tabular}




\begin{tabular}{|c|c|c|c|c|c|c|c|}
$\begin{array}{c}\text { Cavitation } \\
\text { Type }\end{array}$ & $\begin{array}{c}\text { Tip } \\
\text { Vortex }\end{array}$ & Tip Vortex & Tip Vortex & Tip Vortex & Tip Vortex & Tip Vortex & Tip Vortex \\
\hline $\begin{array}{c}\text { Inception } \\
(\mathrm{RPM})\end{array}$ & 1903 & 1856 & 1828 & 1793 & 1875 & 1860 & 1803 \\
\hline $\begin{array}{c}\text { Desinence } \\
(\mathrm{RPM})\end{array}$ & 1914 & 1860 & 1832 & 1797 & 1879 & 1870 & 1807 \\
\hline $\mathrm{J}_{\text {Inception }}$ & 0.589 & 0.604 & 0.614 & 0.625 & 0.598 & 0.603 & 0.622 \\
\hline$\sigma_{\text {Inception }}$ & 0.303 & 0.316 & 0.325 & 0.337 & 0.31 & 0.314 & 0.332 \\
\hline
\end{tabular}

In Table 4 the inception cavitation number $\left(\sigma_{i}\right)$ is defined based on the resultant velocity as follows:

$$
\sigma_{i}=\frac{P_{s t}-P_{v}}{0.5 \rho V_{R}^{2}}
$$

where the resultant velocity $\left(V_{R}\right)$ is defined by

$$
V_{R}=\sqrt{V^{2}+(0.7 \pi n D)^{2}}
$$

In addition to the RPM values corresponding to the cavitation inception and desinence points, Table 4 also includes the corresponding advance coefficients $\left(J_{\text {inception }}\right)$ to be able to relate them to the radiated noise levels. Table 4 illustrates the effect of the varying shaft inclinations on the inception/desinence points.

Figure 8 shows inception trends for positive and negative angles of shaft inclination angle. Inception occurred earliest at the higher inclination angles. While this effect was not symmetrical with angle at the Atmospheric condition, it became more so with the increasing vacuum in the case of the medium and high level of vacuum conditions.

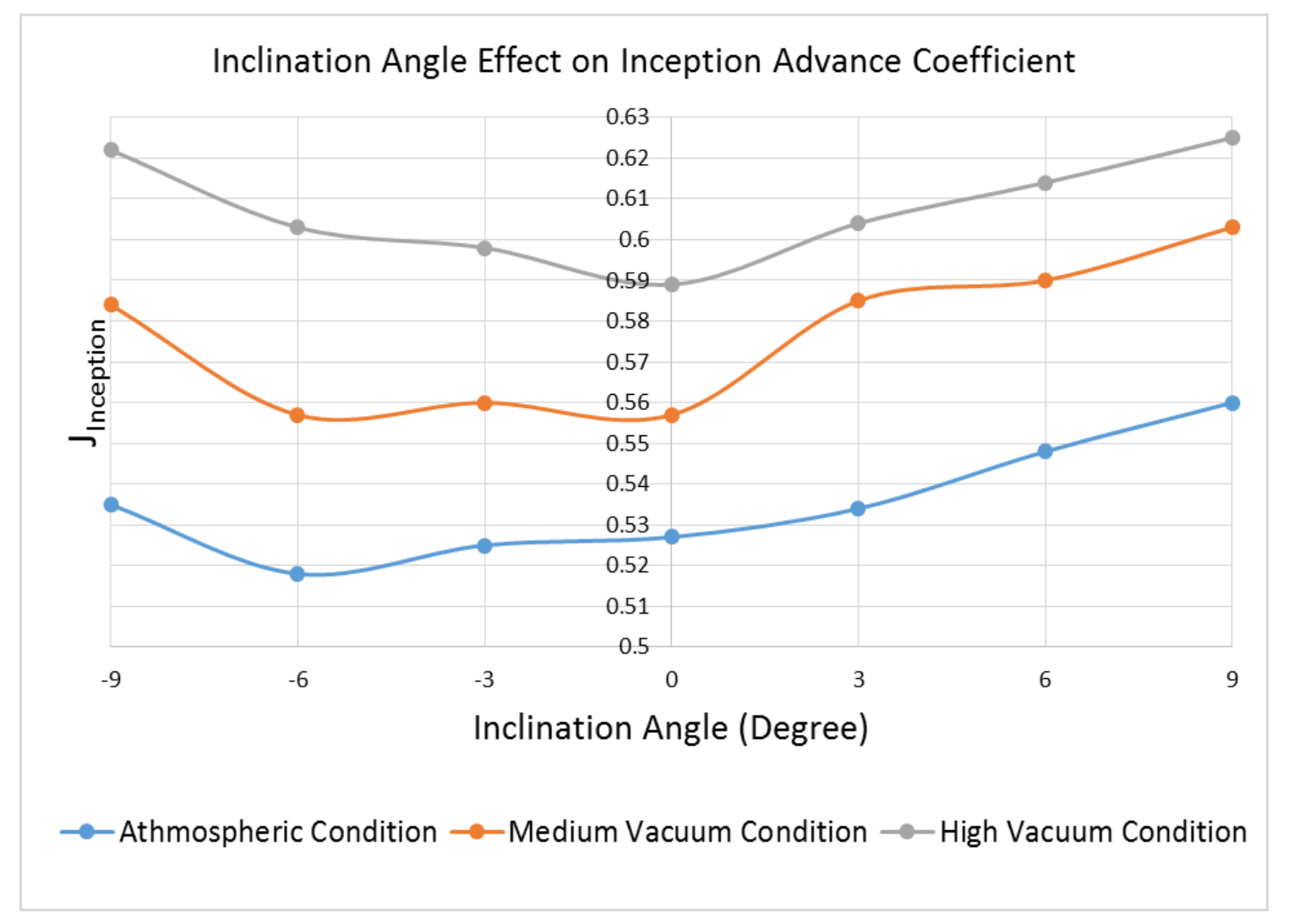

Figure 8 Variation of cavitation inception $\mathbf{J}$ number (Advance Coefficient) with respect to inclination angles 


\section{NOISE MEASUREMENTS}

Noise measurements were also carried out at the 7 different shaft inclination angles and 3 different cavitation conditions. The measurements were recorded using a Bruel and Kjaer type 8103 miniature hydrophone mounted in a water filled, thick walled steel cylinder placed on the outside of the tunnel's plexiglas window. This cylinder was glued onto the starboard window level with the centre of the propeller boss when the shaft inclination is zero and at a horizontal distance of $0.61 \mathrm{~m}$ from the shaft centreline, as shown in Figure 9 (top picture). The hydrophone signals were collected by further Bruel and Kjaer hardware and software; in this case a PC based "PULSE" digital acquisition and analysis software system up to a frequency of $25 \mathrm{kHz}$, was used.

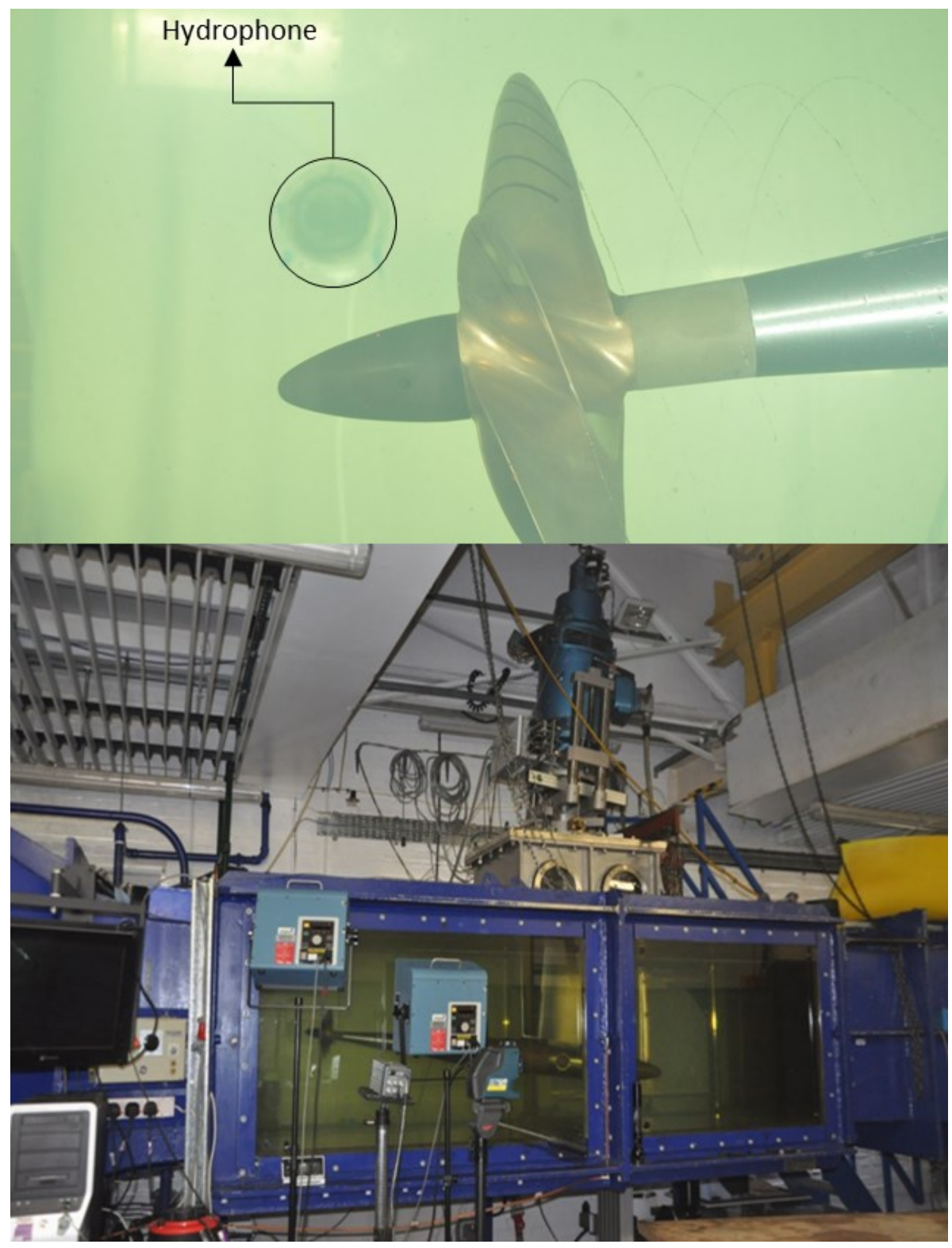

Figure 9 A view of hydrophone glued on the side window (top photo); An overall view of the dynamometer with inclined shaft arrangement in test section of tunnel (bottom photo).

\subsection{Analysis and Presentation of the Noise Results}

A common practice in the analysis and presentation of the noise levels is to reduce the measured values of Sound Pressure Levels (SPL) in each 1/3 octave band to an equivalent $1 \mathrm{~Hz}$ bandwidth by means of the correction formula recommended by (ITTC 1987) as follows.

$$
\mathrm{SPL}_{1}=\mathrm{SPL}_{m}-10 \log \Delta f
$$

where $S P L_{l}$ is the reduced sound pressure level to $1 \mathrm{~Hz}$ bandwidth in $\mathrm{dB}$; re $1 \mu P a$, $S P L_{m}$ is the measured sound pressure level at each centre frequency in $d B$; re $1 \mu \mathrm{Pa}$ and $\Delta f$ is the bandwidth for each $1 / 3$ Octave band filter in $\mathrm{Hz}$. 
The ITTC also required that the sound pressure levels be corrected to a standard measuring distance of $1 \mathrm{~m}$ using the following relationship.

$$
\mathrm{SPL}=\mathrm{SPL}_{1}+20 \log (r)
$$

Where SPL is the equivalent sound pressure level ( $1 \mathrm{~Hz}$ at $1 \mathrm{~m}$ distance) in $\mathrm{dB}$; re $1 \mu \mathrm{Pa}$ and $r$ is the reference distance for which the noise level was measured.

The PULSE settings, for $1 / 3$ octave band analysis, are shown in Table 5 . The software has been set up to trigger the data acquisition every 0.25 seconds to record and analyse the acquired data. This resulted in a series of processed measurements which found to be best presented in a waterfall format within the user interface of the software in order to eliminate the influence of any instantaneous disturbance. With regards to the various settings that are presented in the Table 5, the measurements are made in $1 / 3$ octave bands with a range as low as $20 \mathrm{~Hz}$ up to $20 \mathrm{kHz}$. As it is a standard for underwater acoustics; no weighting was applied to the analyzed spectral levels and they were converted in to dB levels by using the reference pressure value of 1 micro-Pascal

Table 5 Noise Data Acquisition System Settings in PULSE system

\begin{tabular}{|l|l|}
\hline Bandwidth & $1 / 3$ octave \\
\hline Lower centre frequency & $20 \mathrm{~Hz}$ \\
\hline Upper centre frequency & $20 \mathrm{kHz}$ \\
\hline Acoustic weighting & as signal \\
\hline Reference Pressure & $1 \mu \mathrm{Pa}$ \\
\hline
\end{tabular}

SPL vs Frequency plots of total noise spectra data (i.e. the propeller plus the tunnel background noise) can be found in (Aktas et al. 2014) for all the measured conditions. The data show the effects of the varying advance coefficients, inclination angles and cavitation numbers as stated in Table 1.

Figure 10 is a typical presentation of the noise spectra over a $20 \mathrm{kHz}$ frequency range displaying the effect of varying shaft inclinations at a fixed $J$ and high vacuum condition (low cavitation number).

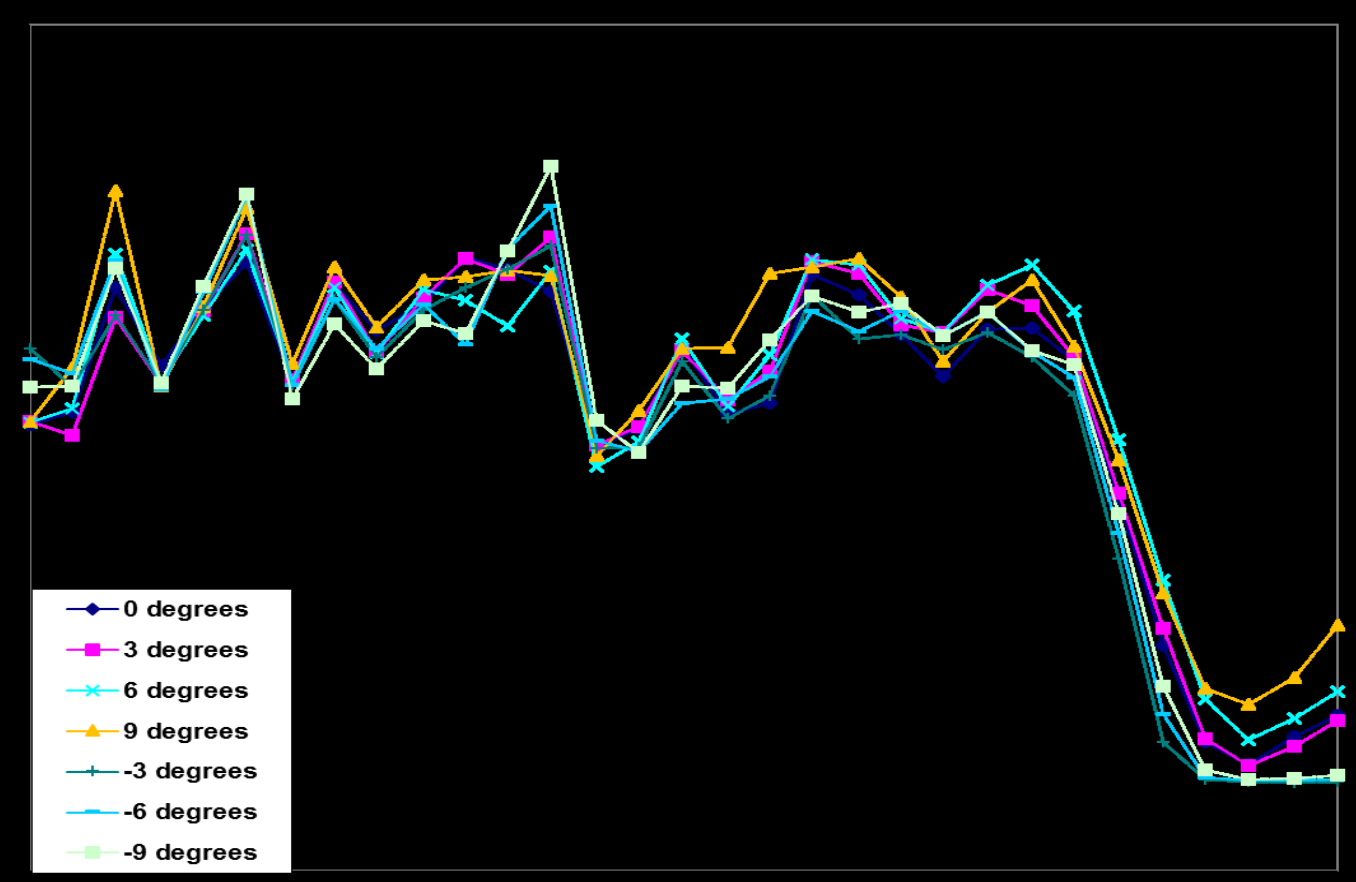


Figure 10 Comparison of noise levels at varying inclination angles at advance coefficient of $J=0.60$ under high vacuum condition

Figure 11 gives qualitative information on the background noise level of the Emerson Cavitation Tunnel. The figure also presents SPL spectra of the propeller corresponding to the $+6^{\circ}$ inclination angle at advance coefficient 0.4 for the three cavitation conditions as given in Table 1.

In order to have a better understanding of the trends in the noise spectra at various conditions, the measured noise data were extracted and presented in Figure 12 at three fixed frequencies: namely $630 \mathrm{~Hz}, 6.3 \mathrm{kHz}$ and $20 \mathrm{kHz}$. These correspond to frequency ranges where the SPL amplitudes were significantly distinct from the background noise and showed strong variations with the advance coefficient and shaft inclination angle.

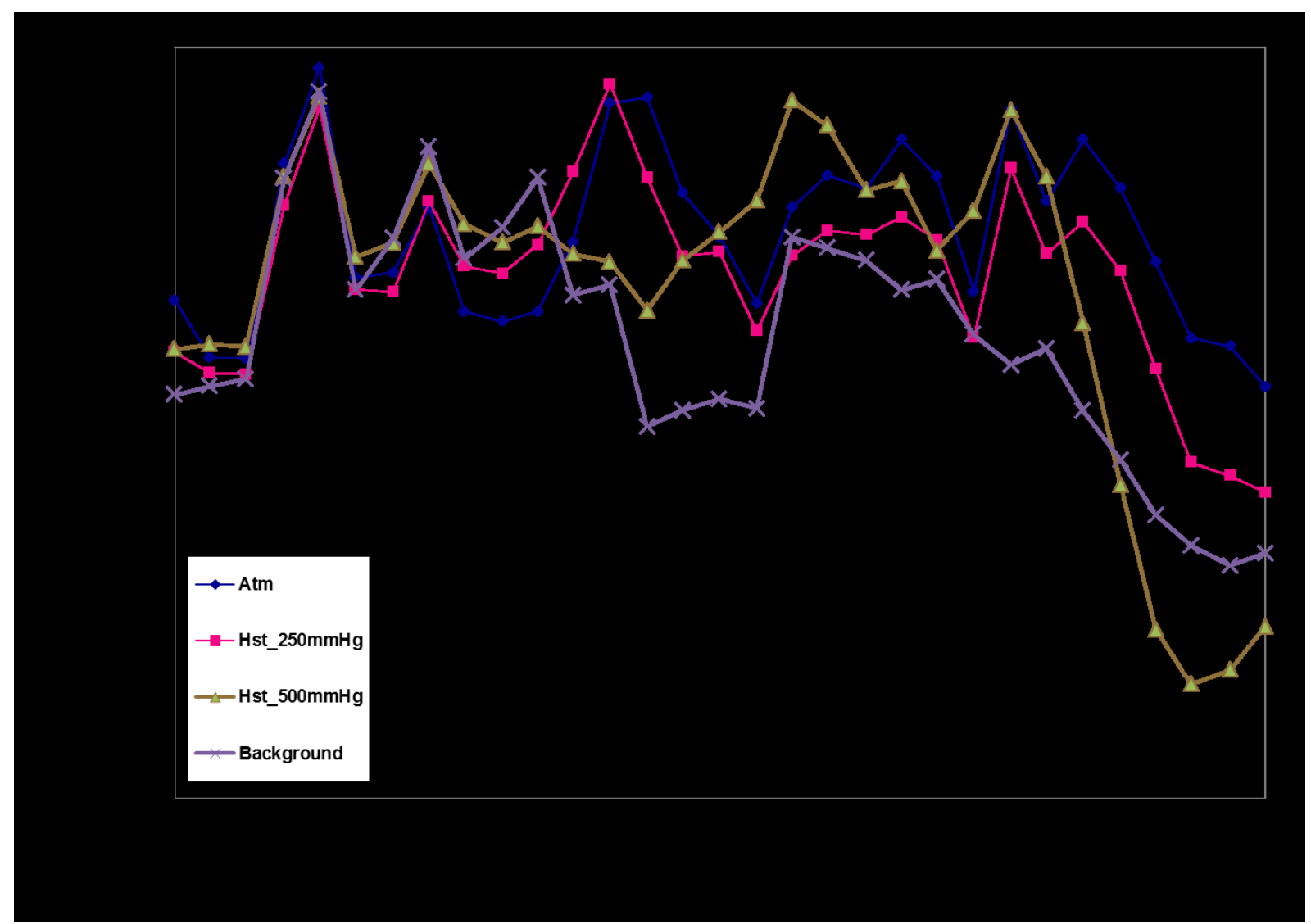

Figure 11 Background noise level spectrum (at Atmospheric cond.) and SPL for $6^{0}$ inclination at $\mathrm{J} 0.4$ (at various cavitation cond.)

In Figure 12 the effect of varying advance coefficients on the SPL are shown for the systematically varied shaft angles and for three cavitation conditions at $630 \mathrm{~Hz}$. The SPLs show relatively less sensitivity to the variations in $J$ except for three distinct J's, where the peak SPL values were recorded. It is considered that these peaks were due to the strong tip vortices shown in the selected cavitation images in Figure 13.

This frequency was also close to the 4th blade harmonic. In order to illustrate the effect of the shaft inclination further, three cross-plot curves were extracted and shown in Figure 14 for systematically varied advance coefficients and for three cavitation conditions at $630 \mathrm{~Hz}$. These cross plots do not show any significant asymmetry for the positive and negative angles of the shaft inclination across the three cavitation conditions imposed. Similar plots for the SPLs are also shown in Figure 15 for $6.3 \mathrm{kHz}$. In the first group of these plots, Figure 14, the noise levels appear to increase in a near monotonic manner from high to low $J$-values at each of the three-cavitation conditions whilst in the second group of the plots, Figure 15 , a little asymmetry with the angle of inclination can be observed, although there is a weak tendency towards higher levels for the positive inclination angles.

During the tests tip vortex and sheet cavitation were the main types observed together with their complex interaction at the blade trailing edge. This interaction was also reflected in the noise levels for certain operating conditions. This was particularly strong at $J=0.4$ for trailing edge vortex breakdown due to interaction with the sheet cavity extending 
downstream and was independent of the flow inclination angles. This phenomenon is illustrated in Figure 16 for the zero and $6^{\circ}$ shaft inclination together with its consequent effect on the SPL's as shown in Figure 15 which represents the impact of the phenomena by the elevation of the spectral levels for all inclination angles at $J=0.4$ for the high vacuum condition (i.e. bottom graph). Similar observations were also given in e.g. (Bark 1986; Bark 1988; Konno et al. 2002)

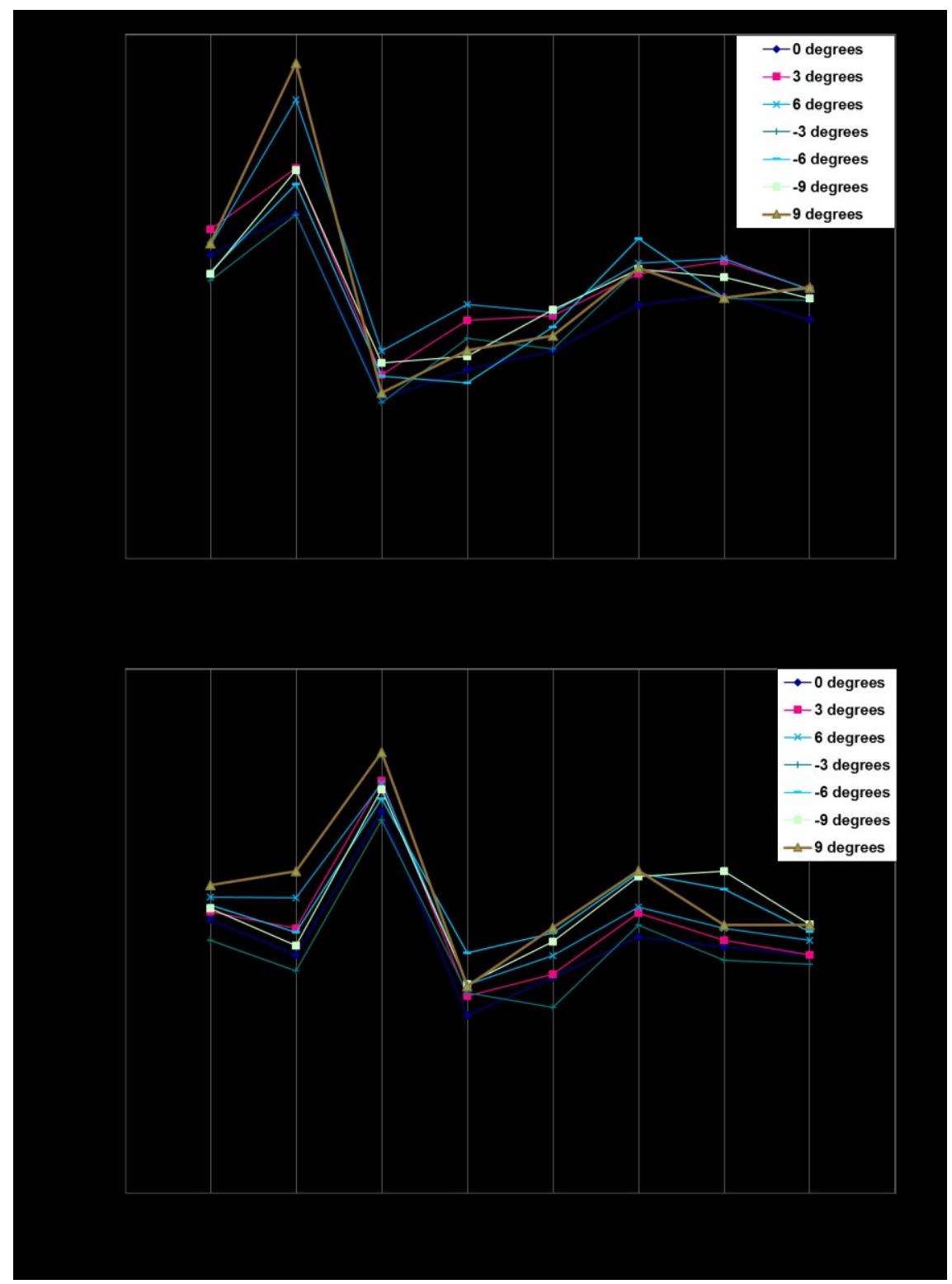




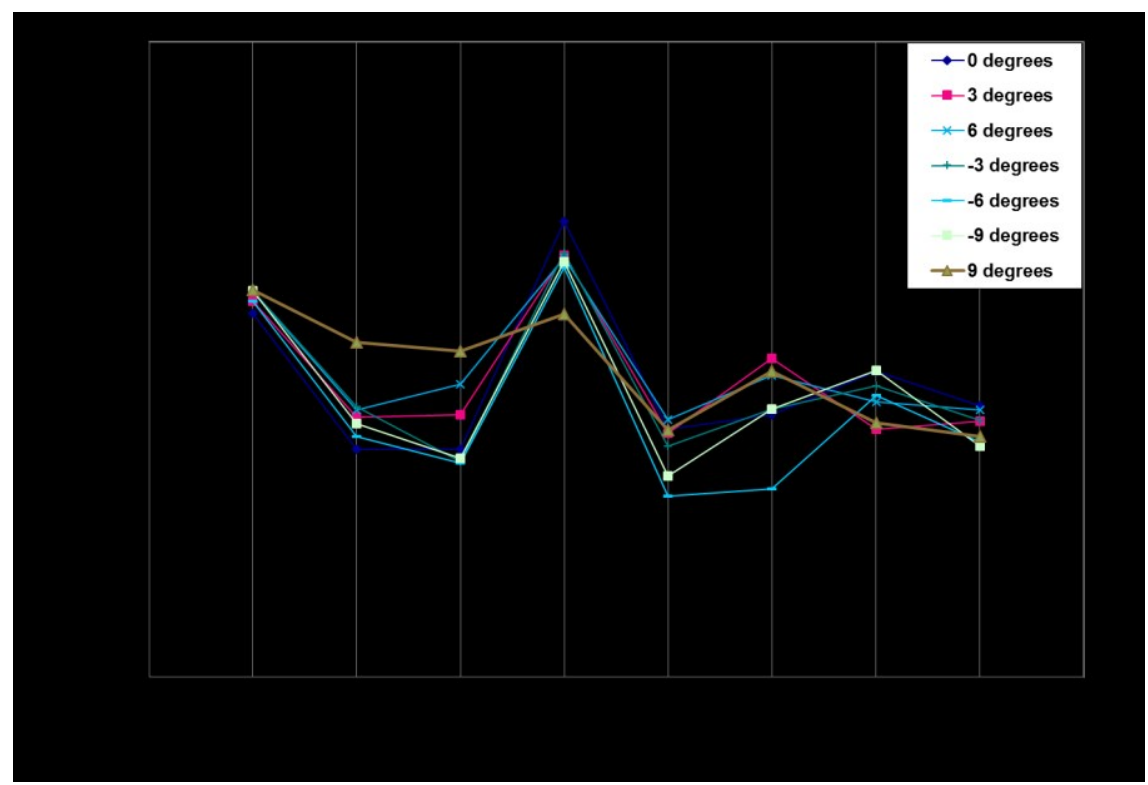

Figure 12 Comparison of noise levels for varying shaft inclination angles on advance coefficients under different cavitation conditions at $630 \mathrm{~Hz}$. 

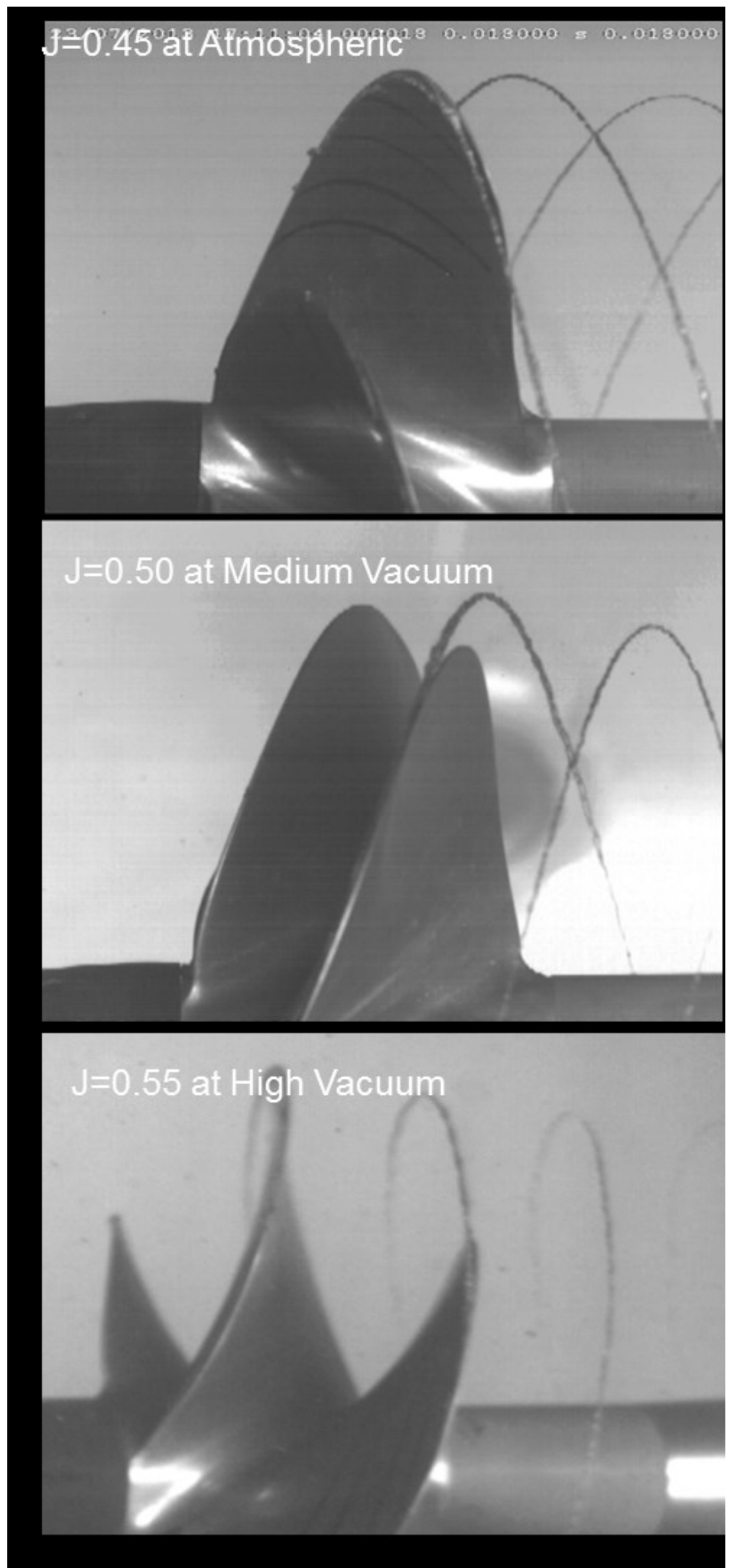

Figure 13 Cavitation observation for varying shaft inclination angles on advance coefficients under different cavitation conditions. 

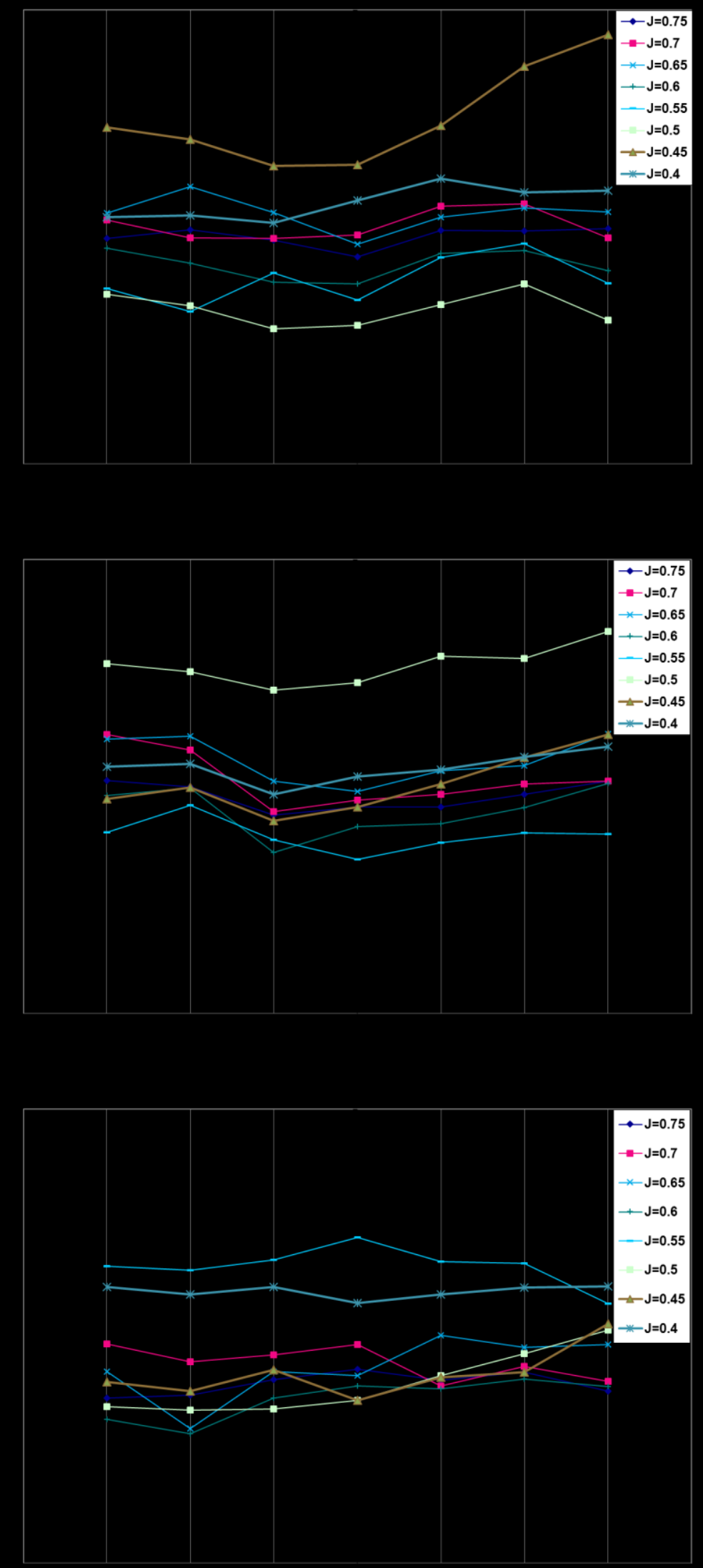

Figure 14 Comparison of noise levels for varying advance coefficients on shaft inclination angles under different cavitation conditions at $630 \mathrm{~Hz}$ 

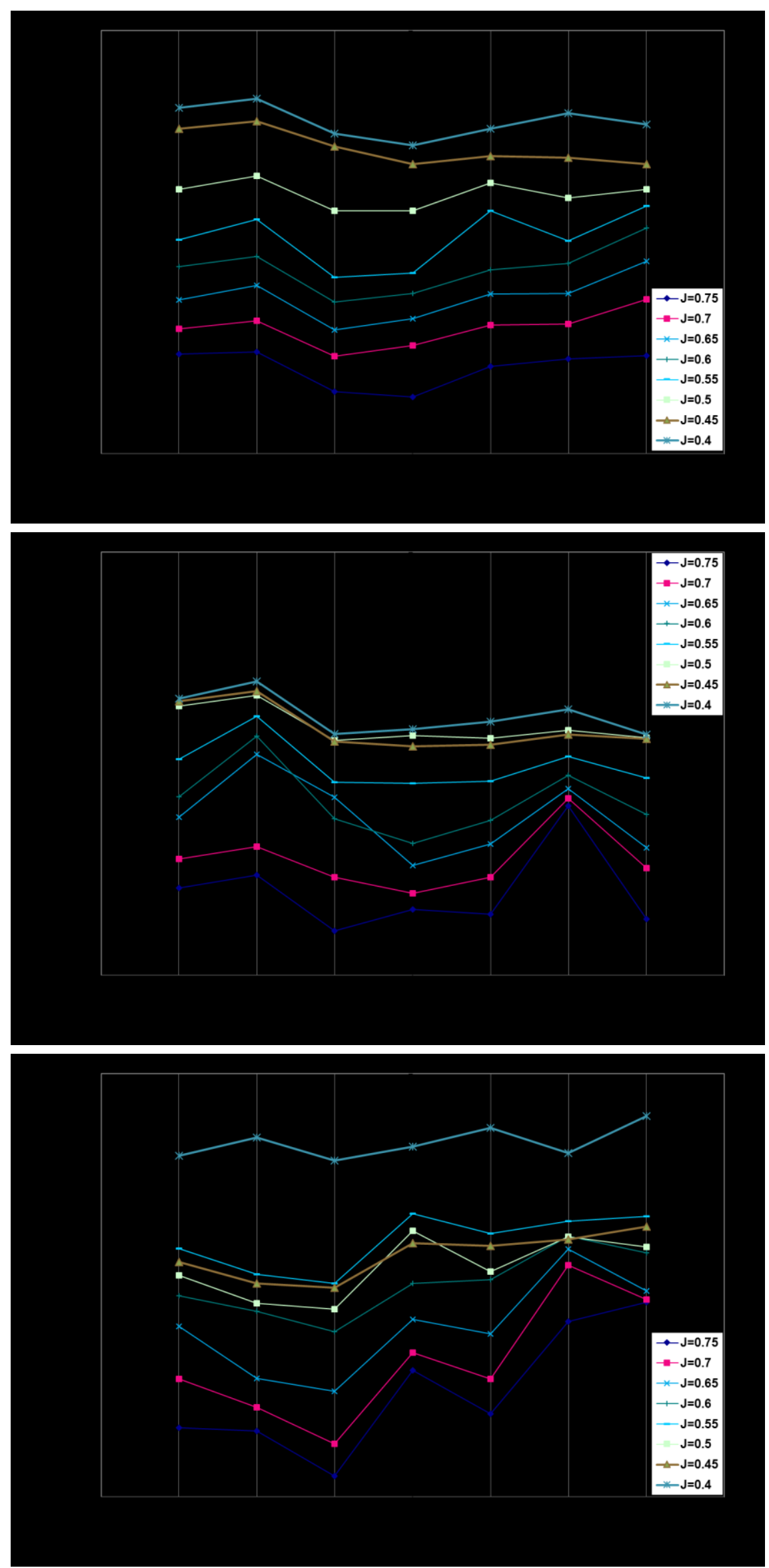

Figure 15 Comparison of noise levels for varying advance coefficients on shaft inclination angles under different cavitation conditions at $6.3 \mathrm{kHz}$. 


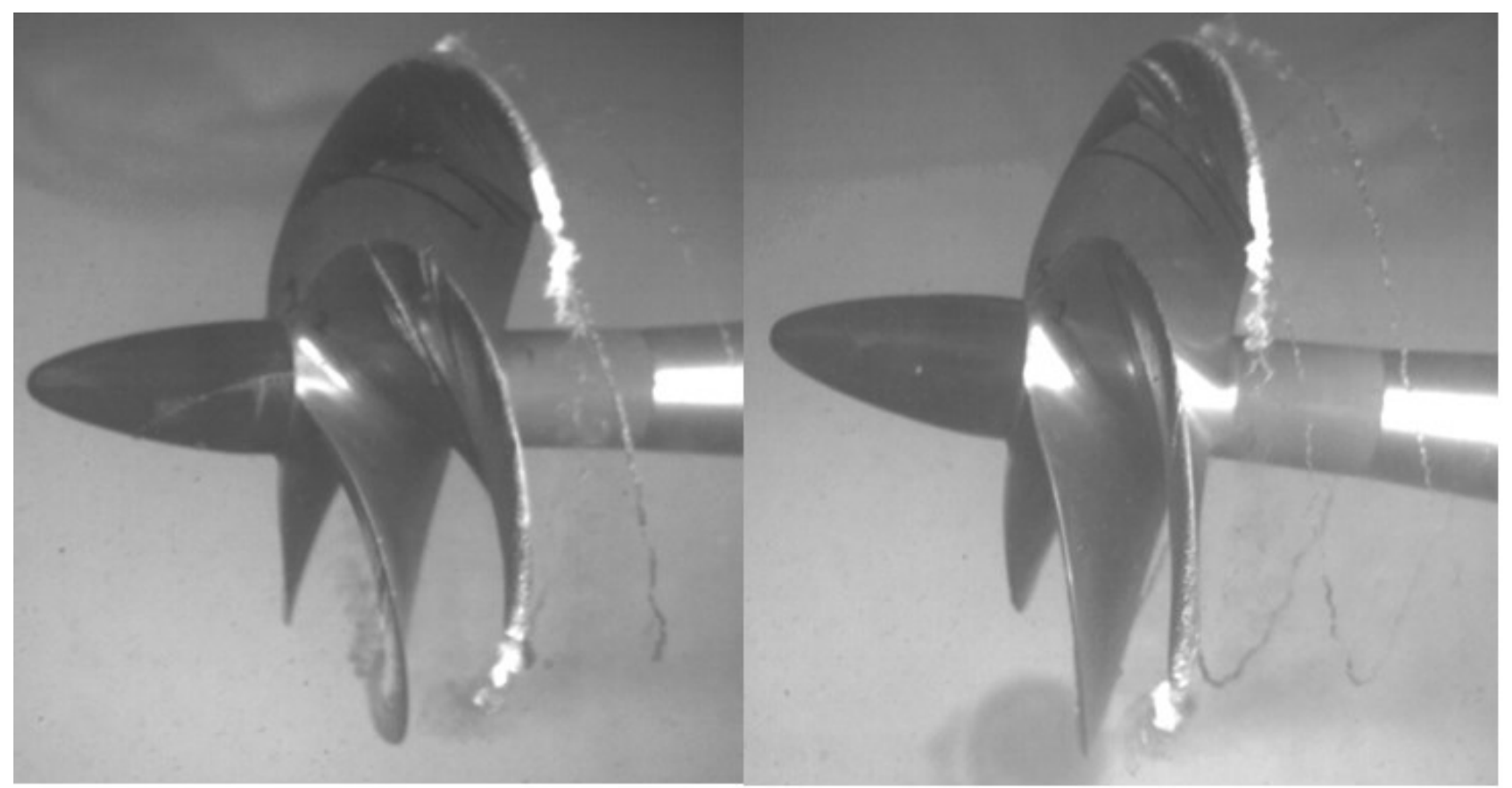

\section{Zero shaft inclination, high vacuum $\quad+6 \mathrm{deg}$ shaft inclination, high vacuum}

Figure 16 Tip vortex breakdown due to interaction with the sheet cavitation extension at $\mathrm{J}=0.4$

\section{DISCUSSION}

7.1 Open water efficiency performance

Effects of the shaft inclination on all test cases are nearly similar for the propeller open water performance curves, namely, showing discernable differences in the torque coefficient $\left(\mathrm{K}_{\mathrm{Q}}\right)$ at $-3^{\circ},-6^{\circ}$ and $-9^{\circ}$ inclination angles and hence on the propeller efficiency $\left(\eta_{0}\right)$ curves. Figure 5 typically shows this trend in the high vacuum condition. As theoretically expected, the inflow velocity is not responsive to the direction of the inclination angle that is in a cosine function. In other words the cosine convention being the same for both minus and plus inclination angles, it sustains the efficiency of the propeller. This can be shown in Figure 17 where no discernable variation in the performance coefficients can be detected with the variations in the inclination angles whilst for the high vacuum condition the loss of thrust and torque is evident due to the cavitation extent. The effect of the different vacuum (cavitation) conditions had similar trends in $K_{T}, K_{Q}$ and $\eta_{0}$ for the Atmospheric and medium cavitation conditions, hence making it difficult to quantify the effect of the inclination under these conditions. It was observed that the increasing vacuum generally reduced the open water efficiency of the propeller at all inclination angles and this effect was also found to be dependent on the $J$ range. For instance comparison of the efficiency of the propeller for $0^{\circ}$ and $6^{\circ}$ has shown as high as $10 \%$ difference at the higher end of the advance coefficient range. But this variance diminishes as the advance coefficient is lowered. 

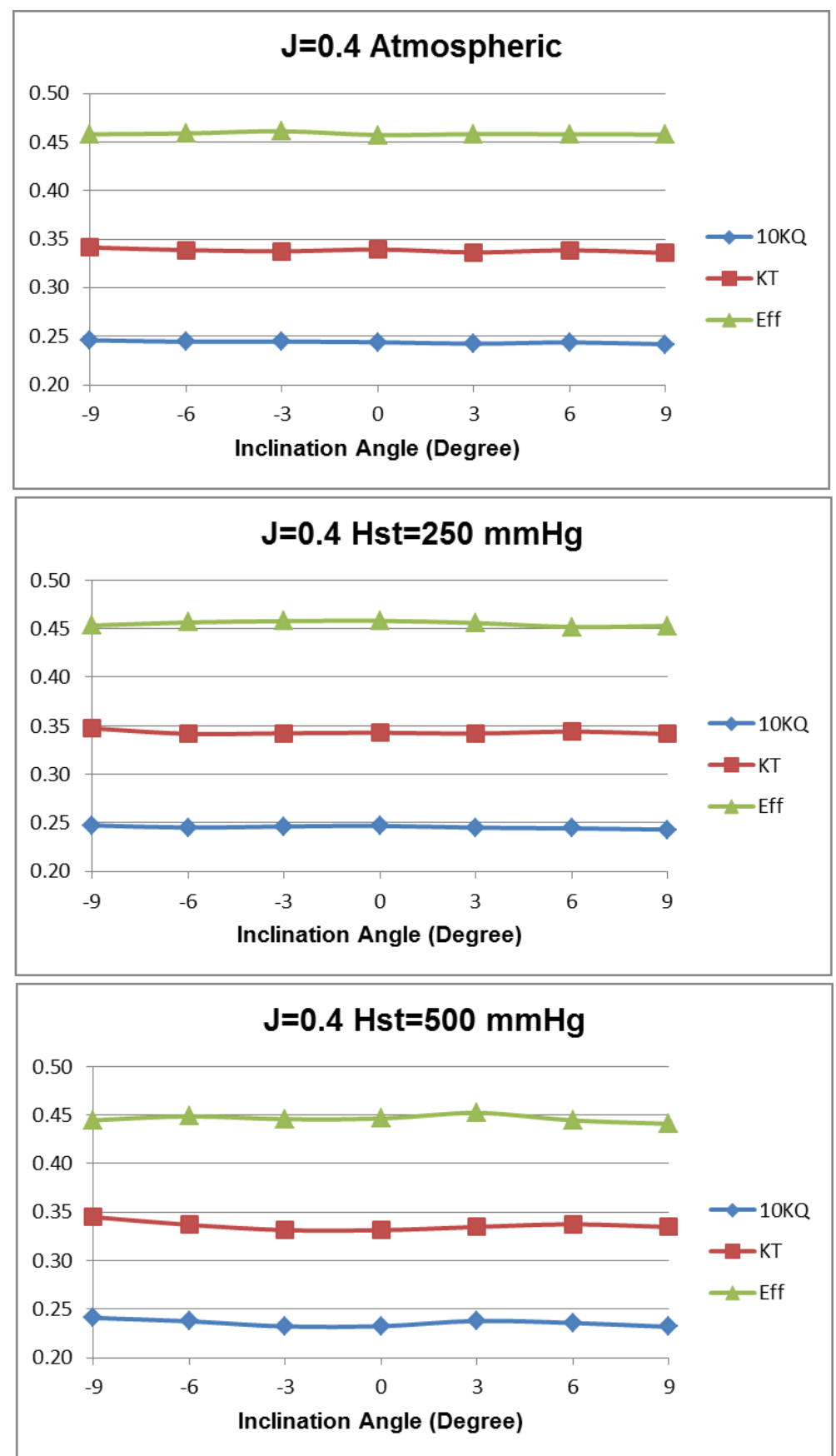

Figure 17 The Non-Dimensional Performance Coefficients at $\mathbf{J}=\mathbf{0 . 4}$ for different vacuum conditions

\subsection{Cavitation observations}

Cavitation inception observations (Figure 8) showed that as the inclination angle was increased the cavitation inception $J$ - value increased for the medium and high vacuum conditions. However for the Atmospheric condition this trend was different by a smaller range of $J$ - values for the negative inclination angles.

Positive shaft inclination stimulated earlier inception on the blades. Overall the inclination angle was observed to initiate an earlier inception for all angles and at all cavitation conditions except the Atmospheric condition. The difference observed at the Atmospheric condition can be attributed to the axial flow speed map of the tunnel and to the reduced number of nuclei available in the circulating water.

Trends in the developed cavitation pattern observations are discussed for the applied three vacuum (cavitation) conditions as follows: 
Atmospheric condition: the propeller model the cavitation-free range was above $J=0.515$ for all values of the shaft inclination angle. Below this $J$ value, two distinct types of cavitation patterns, i.e. tip vortex and sheet cavitation were observed, however, with only slight differences in the extent and strength for the inclined cases relative to the level shaft inclination case. Figure 18 shows images for zero shaft angle.

Medium vacuum condition: The cavitation-free range was observed above $J=0.55$. Below this range it was observed that the strength of the tip vortices was increased compared to the Atmospheric condition and also displayed distinct nodes in their structures behind the blade training edges, as shown typically in Figure 19. However, similar to the Atmospheric condition, it was difficult to observe clear differences in the cavitation structures for the same positive and negative shaft angles.

High vacuum condition: The cavitation-free range was above $J=0.59$, including variations in the inclination angle. Figure 16 and Figure 20 show typical examples for this condition with larger tip vortex structures than observed at the lower vacuum conditions. The cavitation appeared to be similar over the range of shaft inclination angle. However, there appeared to be more sheet cavitation at $J=0.4$ and -6 degrees shaft inclination than at the moderate cavitation condition. A wide extent of sheet cavitation was also shown over the blade area combined with severe trailing edge tip vortex collapse.

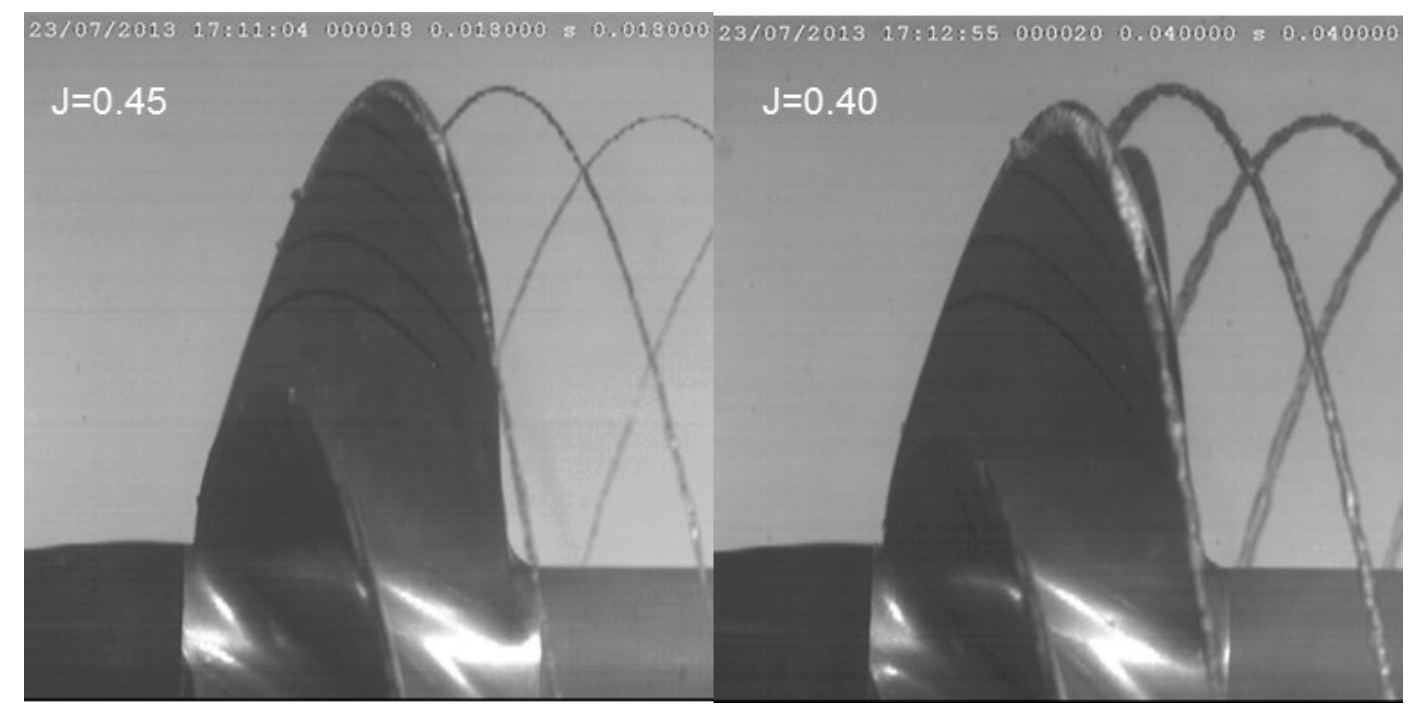

Figure 18 Cavitation patterns at $0^{\circ}$ inclination angle under Atmospheric condition

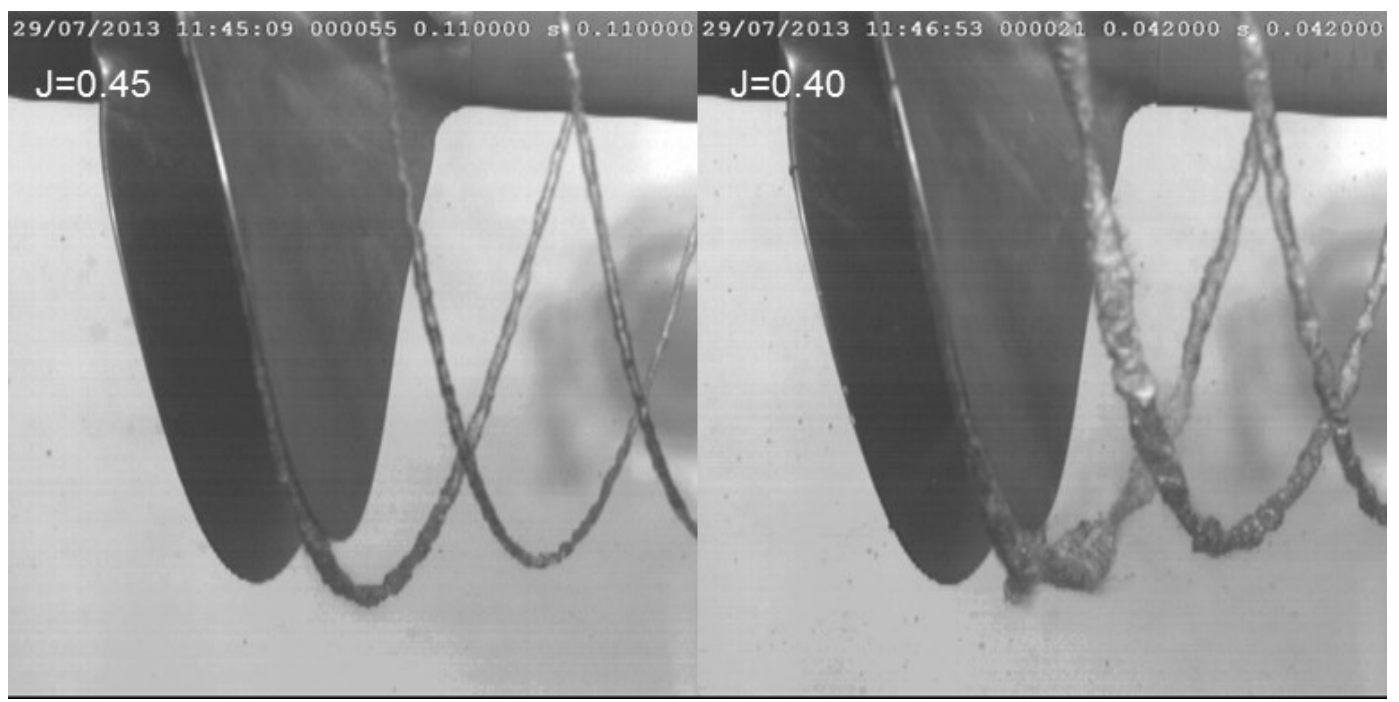

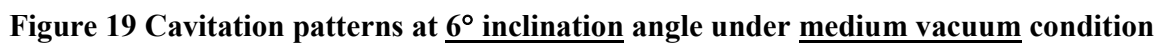




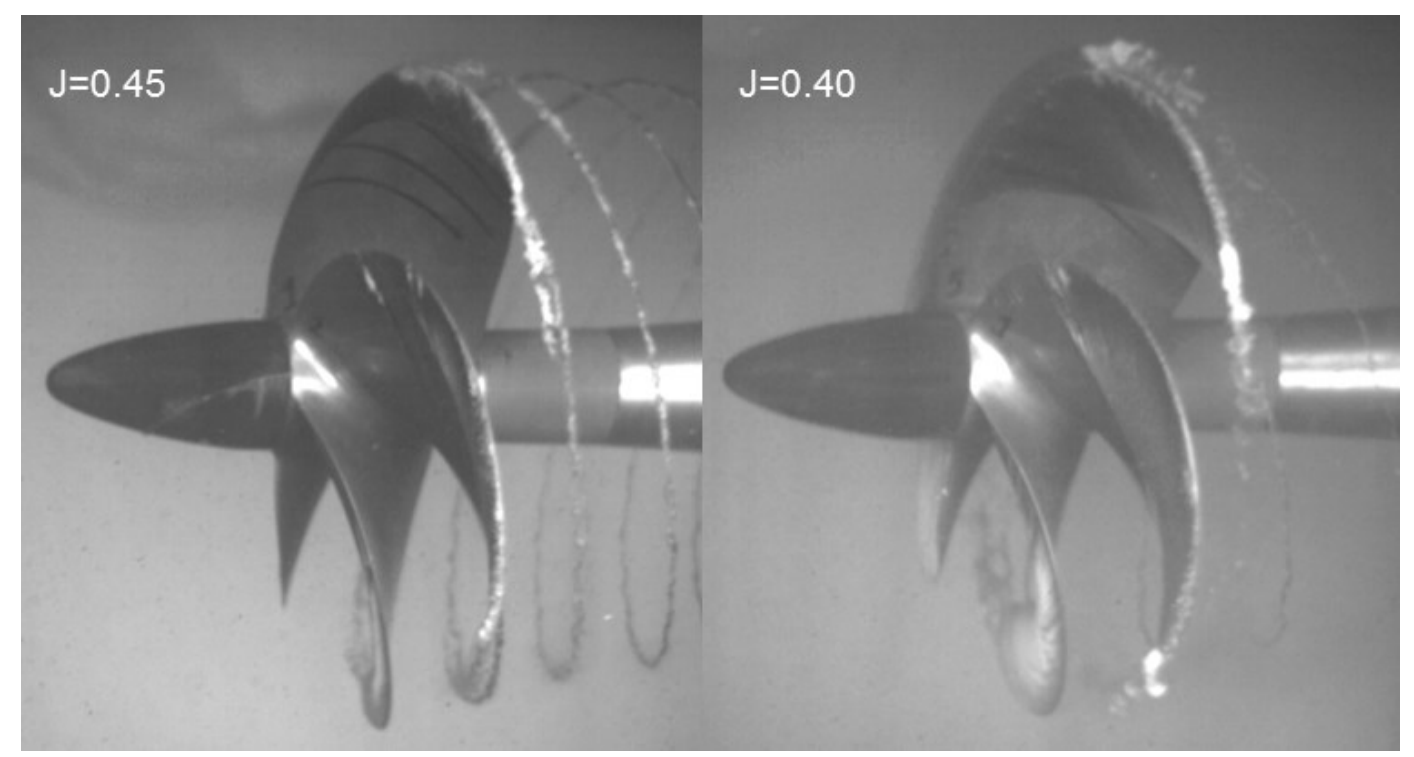

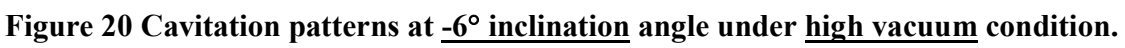

\subsection{Noise measurements}

The noise measurements presented here contain the combined propeller and background noise; no correction was made for the background noise of the tunnel. A vibration survey of the tunnel carried out earlier showed that the frequencies of the structural vibration generated by the dynamometer and impeller to be in the region below $100 \mathrm{~Hz}$. Therefore, it is most likely that the noise levels due to the blade rate frequency ranging from $125 \mathrm{~Hz}$ to $250 \mathrm{~Hz}$ and its harmonics, together with structural vibration, would be affected by these effects in the frequency region up to $1000 \mathrm{~Hz}$. In other words the contribution of the major noise sources during the operation of the tunnel imposed a rather noisy environment for frequencies lower than $1000 \mathrm{~Hz}$ as shown, typically in Figure 11.

However the analyzed results in Figure 12 for the effect of advance coefficient indicated that, as the advance coefficient reduced, the noise levels increased in the high frequency range (above $1000 \mathrm{~Hz}$ ) for $J=0.75$ to 0.55 under the Atmospheric condition. Below $J=0.55$ the noise levels were almost similar.

For the medium cavitation condition a similar trend was also observed up to $J=0.50$ in the high frequency range. However at $J=0.45$ and $J=0.40$ the noise level reduced slightly in the high frequency range, demonstrating the fact that the medium and high vacuum conditions may have introduced a cushioning effect in the collapse stage of bubbles which may have reduced the noise levels as conjectured by Ross (Ross, 1987) and discussed in the18th ITTC (ITTC, 1987).

At the Atmospheric condition, the effect of the shaft inclination showed that the noise levels in the low frequency range seemed to be similar, regardless of the inclination angle. In the high frequency range, the noise levels at the $9^{\circ}$ inclination angle case were the highest of all the inclination angles tested. This trend changed in the medium cavitation condition as the $6^{\circ}$ inclination angle case became the noisiest, while the $9^{\circ}$ case was the quietest.

For the higher frequency range a similar behaviour was also observed, however at $J=0.45$ and $J=0.40$ the reductions in the noise levels were more pronounced. This also confirmed the effect of the developed cavitation on the noise levels. As the propeller loading increased the effect of more developed cavitation and possible cushioning effects became more obvious. This trend was also observed at $3^{\circ}$ inclination angle. However, for the $9^{\circ}$ shaft inclination the differences in the comparative noise levels between the Atmospheric and medium vacuum conditions were more prominent than for the $0^{\circ}$ and $3^{\circ}$ cases. At $6^{\circ},-3^{\circ},-6^{\circ}$ and $-9^{\circ}$ inclination angles and in the high frequency range, the comparative noise levels displayed 3 different trends depending on the $J$ range. For $J=0.75$ to 0.65 the noise levels for the Atmospheric and medium vacuum cases were similar; for $J=0.60$ to 0.55 the medium vacuum case displayed higher noise levels; but for $J=0.50$ to 0.40 the Atmospheric condition displayed higher noise levels. It was again observed that more developed cavitation was an effective noise source at low $\mathrm{J}$ number range from 0.50 to 0.40 .

However following the appearance of visible cavitation and the development of stable cavitation, the sound pressure levels were observed to converge. This can be attributed to the earlier inception caused by the shaft inclination and as the 
differences between the extents of developed cavitation reduced the measured SPL levels at different conditions started to radiate almost exact spectral levels.

\subsection{Concluding remarks}

The main focus of this paper has been on flow-unsteadiness caused by systematically varying shaft inclination especially on the underwater radiated noise of a model propeller. The inclined shaft effect is mainly associated with small craft at relatively high-speed as in the case of The Princess Royal. It is a well-known fact that further unsteadiness to be caused by the hull wake is another important phenomenon contributing into the radiate noise especially for large commercial vessels with no shaft inclination. Although no effect of the hull wake is studied in this investigation this effect on the noise characteristics of large merchant ship propellers has been explored systematically through a major experimental campaign by the present authors and reported recently in Aktas et al (2015a) as part of FP7-SONIC project.

Furthermore the authors have also conducted cavitation tunnel tests with the same model propeller behind the simulated wake of The Princess Royal hull and compared the predicted noise levels based on the model tests with the full-scale noise measurements made with the same vessel as part of FP7 SONIC project as reported in Aktas et al (2015b). These comparisons have indicated reasonable correlations over the low and medium frequency range (up to 500hz) while they were somehow underestimated in the higher frequency range (beyond $1000 \mathrm{~Hz}$ ). The comparison of the data presented in this paper with the full-scale measurements would not be fair due to the absence of the wake effect and hence would be lower than the full-scale.

\section{CONCLUSIONS}

Systematic cavitation tunnel tests were carried out to investigate the open water (efficiency) performance, cavitation and noise characteristics of the model propeller of the UNEW research vessel, The Princess Royal, in uniform (open water) and in inclined flow conditions.

The tests reported in this paper are the first experiments in a round robin campaign organized by the members of the Noise CoP in the HTF. Therefore, while some early conclusions from these tests are given in the paper, the main objectives of the entire test campaign will be achieved when it is finalized in 2015 and hence the final conclusions will be drawn based on the whole campaign. The following conclusions are from the UNEW test campaign.

- The effect of shaft inclination on the propeller open water performance was greater on the torque and hence the propeller efficiency. The effect was asymmetric with shaft positive and negative angles and across the $J$ range. The thrust was relatively insensitive to the change in the shaft angles. The propeller efficiency was reduced with increasing vacuum over the range tested.

- The effect of shaft inclination on the cavitation inception (and desinence) of the tip vortices was clear and this effect was asymmetric in general depending on the direction of the inclination. However this asymmetry was less pronounced towards the higher vacuum levels. The asymmetry for the atmospheric and medium cavitation condition can be attributed to the axial flow profile of the tunnel and to the reduced number of nuclei available in the circulating water.

- Two distinct types of well-developed cavitation patterns (tip vortex and sheet cavitation) were observed together with their complex interactions at the trailing edges of the blades. The extent and strength of these cavitation phenomena were influenced by the change in the inclination angles.

- The presented total noise levels (including the tunnel background noise), showed that, in the low frequency range, the effect of changing the shaft inclination seemed not to be influential, since all the inclined conditions displayed similar noise levels and trends. However this trend changed in the high frequency range depending on the direction of the shaft inclination as well as the vacuum levels applied as in Figure 15.

- The recorded radiated noise levels were found to be highly sensitive to the type and extent of cavitation as well as the frequency range to which the particular cavitation contributed.

\section{ACKNOWLEDGEMENTS}

This research project is funded by the School of Marine Science and Technology (MAST) of Newcastle University (UNEW). The research is part of the Noise Community of Practice (CoP) activities of the Hydro Testing Forum (HTF) under their task of the round robin test campaign with the model propeller of The Princess Royal. The members of the Noise CoP of HTF include CRN-INSEAN, DGA/H, KIOST/MOERI, MARIN, SSPA and UNEW. The Authors thank to Mr. George Politis, the tunnel manager of the Emerson Cavitation Tunnel, for his collaboration and help during the experiments.

\section{REFERENCES}

Abrahamsen, K. A. (2012). 'The ship as an underwater noise source'. ECUA 2012, 11th European Conference on Underwater Acoustics, Edinburgh. July. 
Aktas, B., Korkut, E., Fitzsimmons, P., \& Atlar, M. (2014). 'Systematic cavitation tunnel tests with a propeller in uniform and inclined flow conditions as part of a round robin campaign', MAST Report No: MT-2014-001. Newcastle University, September.

Aktas, B., Atlar, M., Fitzsimmons, P., Shi, W., Turkmen, S., and Sasaki, N., (2015a) 'Systematic cavitation tunnel tests for cavitation noise prediction of commercial ships using a standard series approach', 4 th International Conference on Advanced Model Measurement Technologies for the Maritime Industry, AMT'15, Istanbul, September.

Aktas, B., Turkmen, S., Shi, W., Sampson, R. Fitzsimmons, P. Korkut, M., Atlar, M. (2015b) 'Underwater radiated noise investiagtions of cavitating propellers using medium size cavitation tunnel tests and full-scale trials', $\underline{4 \text { th Intl }}$ Symposium on Marine Propulsors, SMP'15, Austin, USA, June.

Arveson, P., \& Vendittis, D. (2000). 'Radiated noise characteristics of a modern cargo ship'. The Journal of the Acoustical Society of America'. 107(1), pp 118-129.

AMT'11. (2011). 2nd Intl. Conference on Advanced Model Measurement Technology for the EU Maritime Industry, AMT'11, Newcastle University, Newcastle Upon Tyne. April

Atlar, M. (2011). 'Recent upgrading of marine testing facilities at Newcastle University', 2nd Intl. Conference on Advanced Model Measurement Technology for the EU Maritime Industry, AMT'11, Newcastle University, Newcastle upon Tyne. April .

Atlar, M, Baktas, B., Sampson, R., Seo, K-C, Ignazio, M.,V., Fitzsimmons, P. (2013), 'A multi-purpose marine sciene \& technology research vessel for full-scale observations and measurements', 3rd Intl Conference on Advanced Model Measurement Technologies for the Maritime Industry, AMT'13, Gdansk, September.

AMT'13. (2013). 3rd Intl Conference on Advanced Model Measurement Technologies for the Maritime Industry, AMT'13, Gdansk, September.

Bark, G. (1986). 'Development of violent collapses in propeller cavitation'. International Symposium on Cavitation and Multiphase Flow Noise', Proc. ASME Symposium, Anaheim, CA, USA, FED 45, pp 65-75.

Bark, G. (1988). 'On The mechanisms of propeller cavitation noise'. PhD thesis, School of Mechanical Engineering. Chalmers University, Goteborg.

Carlton, J. (2012). Marine propellers and propulsion. 3rd ed. Butterworth-Heinemann. Oxford.

Gutsche, F. (1964). 'Untersuchung von Schiffsschrauben in schräger Anströmung' Schiffbanforschung. Translation in DTMB. March

Hadler, J. B. (1966). 'The Prediction of Power Performance on Planing Craft.' Trans. SNAME, Vol. 74, New York. November.

Hildebrand, J. A. (2005). 'Impacts of anthropogenic sound' Marine mammal research: conservation beyond crisis. The Johns Hopkins University Press, Baltimore, Maryland. pp 101-124.

IMO. (2011). 'Noise from commercial shipping and its adverse impact on marine life development of an international standard for measurement of underwater noise radiated from merchant ships'. MEPC 62nd session agenda item 19. pp. 61-62.

ITTC (1987). Report of The Cavitation Committee, 18th International Towing Tank Commitee. Kobe, Japan.October. pp. $159-220$

ITTC. (2011). Model - Scale Cavitation Test. 26th ITTC - Recommended Procedures and Guidelines. Rio de Janeiro.

ITTC. (2014) Specialist Committee on Hydrodynamic Noise Final Report and Recommendations to the 27th ITTC. Copenhagen.

Konno, A., Wakabayashi, K., Yamguchi, H., Maeda, M., Ishii, N., Soejima, S., \& Kimura, K. (2002). 'On the mechanism of the bursting phenomena of propeller tip vortex cavitation'. Journal of Marine Science and Technology6(4). pp 181192.

Kozhukharov, P. G., \& Sadovnikov, M. Y. (1983). 'Investigation on cavitating screw propellers operating in oblique flow'. 2nd International Conference on Cavitation. Edinburgh.

McKenna, M. F., Ross, D., Wiggins, S., \& Hildebrand, J. A. (2012). 'Underwater radiated noise from modern commercial ships'. Journal of Acoustical Society of America. pp 92-103.

MCR. (2011). 'Cruise report for research projects conducted from R/V Song of the Whale in French and UK waters of the English Channel', The Final Report. http://www.marineconservationresearch.co.uk/downloads/, Retrieved on 14 October 2014, 
MEPC (2010) 'Noise From Commercial Shipping and Its Adverse Impacts on Marine Life'. Marine Environment Protection Committee. MEPC 60/18. December.

Ross, D. (1987). 'Mechanics of Underwater Noise'. Peninsula Publishing. California.

SONIC. (2012). 'Suppression Of underwater Noise Induced by Cavitation'. EC-FP7, Grant agreement no: 314394.

Taniguchi, K., Tanibayashi, H., \& Chiba, N. (1969). Investigation into the Propeller Flow Cavitation in Oblique'. Mitsubishi Technical Bulletin No. 45, March. 